\title{
A Concise Synthesis and Cellular Evaluation of 3'-Formyl-4',6'-dihydroxy-2'-methoxy-5'-methylchalcone (FMC) and Its Analogues
}

\author{
Xiang Zhuo ${ }^{1,2}$, Li En-Zhen ${ }^{2}$, Liang Hai ${ }^{2,3}$, Guo Hong-Ju ${ }^{2}$, Shi Ning ${ }^{2}$, Zhang Xue-Hui ${ }^{2}$, \\ Qian Qi-Fang ${ }^{2}$ and Wu Jiu-Hong *1,2 \\ ${ }^{1}$ School of Pharmacy, Fourth Military Medical University; Xi'an 710032, P. R. China; \\ ${ }^{2}$ Department of Pharmacy, 306 Hospital of PLA; Beijing 100101, P. R. China; \\ ${ }^{3}$ College of Pharmacy, Anhui Medical University; Hefei 230032, P. R. China \\ Email: 321xz123@163.com
}

\section{EXPERIMENTAL}

\section{Synthesis}

\section{2,4,6-Trihydroxytoluene (3)}

To a solution of 2,4,6-trihydroxy benzaldehyde (1.54 g, $10 \mathrm{mmol})$ in THF (30 ml) and sodium cyanoborohydride $(1.9 \mathrm{~g}, 30 \mathrm{mmol})$. The solution was stirred for $20 \mathrm{~h}$ (keeping the $\mathrm{pH} 4.0$ ) by adding $1 \mathrm{~N} \mathrm{HCl}$. The reaction mixture was extracted with EtOAc and were washed with brine, dried over $\mathrm{Na}_{2} \mathrm{SO}_{4}$ and concentrated under vacuum. The residue was chromatographed on silica gel with petroleum ether-EtOAc (3:1 to $1: 1 \mathrm{v} / \mathrm{v})$ to provide $3(520 \mathrm{mg}, 37 \%)$, colorless prisms. Compound was characterized by comparing its data with literature values. ${ }^{[1]} \mathrm{Mp}: 212-213{ }^{\circ} \mathrm{C} .{ }^{1} \mathrm{H}-\mathrm{NMR}$ 
$\left(500 \mathrm{MHz}, \mathrm{DMSO}_{6}\right) \delta: 5.89(2 \mathrm{H}, \mathrm{s}, \mathrm{Ph}-3,5), 2.01\left(3 \mathrm{H}, \mathrm{s}, \mathrm{CH}_{3}\right) .{ }^{13} \mathrm{C}-\mathrm{NMR}(125 \mathrm{MHz}$, DMSO-d $\left.{ }_{6}\right) \delta: 157.9,156.8,103.8,95.7$, and 8.3. HRMS m/z: calcd for $\mathrm{C}_{7} \mathrm{H}_{7} \mathrm{O}_{3}$ : $139.0395[\mathrm{M}-\mathrm{H}]^{+}$, found: 139.0408.

\section{2,4,6-Trihydroxy-3-methylacetophenone (4)}

To a solution of trihydroxytoluene $3(1.54 \mathrm{~g}, 10 \mathrm{mmol})$ in HOAc $(30.0 \mathrm{~mL})$ and $\mathrm{Ac}_{2} \mathrm{O}(3.0 \mathrm{~mL})$ at room temperature, then $\mathrm{BF}_{3} \cdot \mathrm{OEt}_{2}(1.7 \mathrm{~mL}, 13 \mathrm{mmol})$ was added. The mixture was heated at $100^{\circ} \mathrm{C}$ for $5 \mathrm{~h}$. The mixture was adjusted to $\mathrm{pH} 4$ by $2 \mathrm{~N}$ $\mathrm{NaOH}$ at $0{ }^{\circ} \mathrm{C}$ then the mixture was extracted with EtOAc and $5 \% \mathrm{MeOH} / \mathrm{EtOAc}$. The combined organic phases were concentrated. The residue was dissolved in $\mathrm{MeOH}$ (30 $\mathrm{mL})$ and $2 \mathrm{~N} \mathrm{NaOH}(30 \mathrm{~mL})$. After stirring at room temperature for $12 \mathrm{~h}$, the mixture was adjusted to $\mathrm{pH} 4$ by $3 \mathrm{~N} \mathrm{HCl}$ at $0{ }^{\circ} \mathrm{C}$, then the volatile solvent was removed in vacuo. The residue was extracted with EtOAc, washed with water, brine, dried over $\mathrm{Na}_{2} \mathrm{SO}_{4}$ and concentrated under vacuum. The residue was chromatographed on silica gel with petroleum ether-EtOAc (3:1 to $1: 2 \mathrm{v} / \mathrm{v})$ to provide $4(1.24 \mathrm{~g}, 68 \%)$, colorless prisms. Compound was characterized by comparing its data with literature values. ${ }^{[2]}$ Mp: 209-210 ${ }^{\circ} \mathrm{C} .{ }^{1} \mathrm{H}-\mathrm{NMR}\left(500 \mathrm{MHz}, \mathrm{DMSO}-\mathrm{d}_{6}\right) \delta: 6.05(1 \mathrm{H}, \mathrm{s}, \mathrm{Ph}-5), 2.67$ (3H, s, $\left.\mathrm{COCH}_{3}\right), 1.88\left(3 \mathrm{H}, \mathrm{s}, \mathrm{CH}_{3}\right)$. HRMS m/z: calcd for $\mathrm{C}_{9} \mathrm{H}_{9} \mathrm{O}_{4}: 181.0501[\mathrm{M}-\mathrm{H}]^{+}$, found: 181.0513.

\section{2,6-Dihydroxy-4-methoxy-3-methylacetophenone (5)}

Compound $4(1.54 \mathrm{~g}, 10 \mathrm{mmol})$ was dissolved in anhydrous acetone $(50 \mathrm{~mL})$, 
then $\mathrm{KOH}$ or $\mathrm{K}_{2} \mathrm{CO}_{3}(30 \mathrm{mmol})$ was added at room temperature. Then methyl iodide $(1 \mathrm{~mL})$ was slowly added to the mixture. The reaction mixture was refluxed for $4 \mathrm{~h}$. The reaction mixture was adjusted to $\mathrm{pH} 4$ by $1 \mathrm{~N} \mathrm{HCl}$ at $0{ }^{\circ} \mathrm{C}$. The volatile solvent was removed in vacuo. The residue was extracted with EtOAc and were washed with brine, dried over $\mathrm{Na}_{2} \mathrm{SO}_{4}$ and concentrated under vacuum. The residue was purified by silica gel using petroleum ether-EtOAc (20:1 to 5:1 v/v) to obtain $5(878 \mathrm{mg}, 57 \%)$, colorless prisms. Compound was characterized by comparing its data with literature values. ${ }^{[3]} \mathrm{Mp}: 186-187^{\circ} \mathrm{C} .{ }^{1} \mathrm{H}-\mathrm{NMR}\left(500 \mathrm{MHz}, \mathrm{DMSO}-\mathrm{d}_{6}\right)$ \&: $6.01(1 \mathrm{H}, \mathrm{s}, \mathrm{Ph}-5), 3.84$ $\left(3 \mathrm{H}, \mathrm{s}, \mathrm{OCH}_{3}-4\right), 2.66\left(3 \mathrm{H}, \mathrm{s}, \mathrm{COCH}_{3}\right), 1.94\left(3 \mathrm{H}, \mathrm{s}, \mathrm{CH}_{3}-3\right) . \mathrm{HRMS} \mathrm{m} / \mathrm{z}$ : calcd for $\mathrm{C}_{10} \mathrm{H}_{11} \mathrm{O}_{4}: 195.0657[\mathrm{M}-\mathrm{H}]^{+}$, found: 195.0675 .

\section{4,6-Dimethoxy-2-hydroxy-3-methylacetophenone (6a) and}

\section{2,4-dimethoxy-6-hydroxy-3-methylacetophenone (6b)}

Compound 4 (1.82g, $10 \mathrm{mmol})$ was dissolved in anhydrous ethanol (50 mL), then $\mathrm{NaOH}(1.66 \mathrm{~g}, 12 \mathrm{mmol})$ was added at room temperature. Then dimethyl sulfate (1.5 $\mathrm{mL}, 12 \mathrm{mmol}$ ) was slowly added to the mixture. The reaction mixture was refluxed for $10 \mathrm{~h}$. Then most volatile solvent was removed in vacuo. The residue was extracted with EtOAc and washed with water, brine, dried over $\mathrm{Na}_{2} \mathrm{SO}_{4}$ and concentrated under vacuum. The residue was purified by silica gel using petroleum ether-EtOAc (5:1 to $1: 1 \mathrm{v} / \mathrm{v})$ to obtain $\mathbf{6 a}(1.24 \mathrm{~g}, 59 \%)$ and $\mathbf{6 b}(294 \mathrm{mg}, 14 \%)$. Compound was characterized by comparing its data with literature values. ${ }^{[3]}$ 6a: colorless prisms, Mp:143-144 ${ }^{\circ} \mathrm{C} .{ }^{1} \mathrm{H}-\mathrm{NMR}\left(500 \mathrm{MHz}, \mathrm{DMSO}-\mathrm{d}_{6}\right) \delta: 13.86(1 \mathrm{H}, \mathrm{s}$, 
$\mathrm{OH}), 6.20(1 \mathrm{H}, \mathrm{s}, \mathrm{Ph}-5), 3.91$ and 3.90 (each s, 3H, $\left.\mathrm{OCH}_{3}-4,6\right), 2.56\left(3 \mathrm{H}, \mathrm{s}, \mathrm{COCH}_{3}\right)$, $1.88\left(3 \mathrm{H}, \mathrm{s}, \mathrm{CH}_{3}-3\right)$. HRMS m/z: calcd for $\mathrm{C}_{11} \mathrm{H}_{13} \mathrm{O}_{4}: 209.0814[\mathrm{M}-\mathrm{H}]^{+}$, found: 209.0832. 6b: colorless oil, ${ }^{1} \mathrm{H}-\mathrm{NMR}\left(500 \mathrm{MHz}, \mathrm{DMSO}-\mathrm{d}_{6}\right) \delta: 12.98(1 \mathrm{H}, \mathrm{s}, \mathrm{OH})$, $6.33(1 \mathrm{H}, \mathrm{s}, \mathrm{Ph}-5), 3.81$ and 3.74 (each s, 3H, $\left.\mathrm{OCH}_{3}-2,4\right), 2.59\left(3 \mathrm{H}, \mathrm{s}, \mathrm{COCH}_{3}\right), 1.96$ (3H, s, $\left.\mathrm{CH}_{3}-3\right)$. HRMS m/z: calcd for $\mathrm{C}_{11} \mathrm{H}_{13} \mathrm{O}_{4}: 209.0814$ [M - H] $]^{+}$, found: 209.0821 .

\section{General procedures for the Claisen-Schmidt reactions}

A solution of $2(2 \mathrm{mmol})$ in $\mathrm{EtOH}(5 \mathrm{~mL})$ and $30 \% \mathrm{KOH}(5 \mathrm{~mL})$ in water containing an appropriate aldehyde $(3 \mathrm{mmol})$ was stirred at room temperature for $36 \mathrm{~h}$. After the reaction was complete by TLC analysis, the mixture was poured into ice-cold $1 \mathrm{~N} \mathrm{HCl}$, then extracted with $\mathrm{CH}_{2} \mathrm{Cl}_{2}$. The extract was washed with brine, dried over $\mathrm{Na}_{2} \mathrm{SO}_{4}$, and concentrated under vacuum. The residue was chromatographed on silica gel with petroleum ether-EtOAc $(20: 1$ to $3: 1 \mathrm{v} / \mathrm{v})$ to obtain the target compound.

3'-Formyl-4',6'-dihydroxy-2'-methoxy-5'-methylchalcone (FMC) (1). 47.2\% yield. Compound was characterized by comparing its data with literature values. ${ }^{[4]} \mathrm{Mp}$ : 123-124 ${ }^{\circ} \mathrm{C} .{ }^{1} \mathrm{H}-\mathrm{NMR}\left(500 \mathrm{MHz}, \mathrm{CDCl}_{3}\right) \delta: 14.01(1 \mathrm{H}, \mathrm{s}$, chelated-OH-6'), $12.67(1 \mathrm{H}$, s, chelated-OH-4'), 10.17 (1H, s, CHO), $7.96(1 \mathrm{H}, \mathrm{d}, J=16.0 \mathrm{~Hz}, \mathrm{H}-\beta), 7.87(1 \mathrm{H}, \mathrm{d}, J$ $=16.0 \mathrm{~Hz}, \mathrm{H}-\alpha), 7.69(2 \mathrm{H}, \mathrm{m}, \mathrm{H}-2,6), 7.47(3 \mathrm{H}, \mathrm{m}, \mathrm{H}-3,4,5), 3.92\left(3 \mathrm{H}, \mathrm{s}, \mathrm{OCH}_{3}\right)$, $2.12\left(3 \mathrm{H}, \mathrm{s}, \mathrm{CH}_{3}\right) .{ }^{13} \mathrm{C}-\mathrm{NMR}\left(125 \mathrm{MHz}, \mathrm{CDCl}_{3}\right) \delta: 192.9[\mathrm{C}(\mathrm{O})], 192.6(\mathrm{CHO}), 169.1$ (C-6’), 167.2 (C-2'), 166.7 (C-4'), 145.0 (C-ß), 134.7 (C-1), 131.0 (C-4), 129.1 (C-3, 
5), 128.7 (C-2, 6), $125.4(\mathrm{C}-\alpha), 108.6\left(\mathrm{C}^{\prime} 5^{\prime}\right), 103.4\left(\mathrm{C}-3^{\prime}\right), 100.14\left(\mathrm{C}^{\prime} 1^{\prime}\right), 66.3$ $\left(\mathrm{OCH}_{3}\right), 6.8\left(\mathrm{CH}_{3}\right)$. HRMS m/z: calcd for $\mathrm{C}_{18} \mathrm{H}_{15} \mathrm{O}_{5}: 311.0919[\mathrm{M}-\mathrm{H}]^{+}$, found: 311.0934.

3'-Formyl-4',6'-dihydroxy-2'-methoxy-5'-methyl-4-bromo-chalcone

(1b).

$54.8 \%$ yield. Yellow needles, Mp: $116-117^{\circ} \mathrm{C} .{ }^{1} \mathrm{H}-\mathrm{NMR}\left(500 \mathrm{MHz}, \mathrm{CDCl}_{3}\right) \delta: 13.91$ $(1 \mathrm{H}, \mathrm{s}$, chelated-OH-6'), $12.66(1 \mathrm{H}, \mathrm{s}$, chelated-OH-4'), $10.15(1 \mathrm{H}, \mathrm{s}, \mathrm{CHO}), 7.87(2 \mathrm{H}$, s, $\mathrm{H}-\alpha, \beta), 7.61(2 \mathrm{H}, \mathrm{m}, \mathrm{H}-3,5), 7.55(2 \mathrm{H}, \mathrm{m}, \mathrm{H}-2,6), 3.90\left(3 \mathrm{H}, \mathrm{s}, \mathrm{OCH}_{3}\right), 2.1(3 \mathrm{H}, \mathrm{s}$, $\left.\mathrm{CH}_{3}\right) .{ }^{13} \mathrm{C}-\mathrm{NMR}\left(125 \mathrm{MHz}, \mathrm{CDCl}_{3}\right) \delta: 193.7$ (CO), $192.3(\mathrm{CHO}), 166.5\left(\mathrm{C}-6^{\prime}\right), 166.0$ (C-2'), 164.4 (C-4'), 138.2 (C- $\beta$ ), 136.5 (C-1), 132.7 (C-3), 132.3 (C-5),132.1 (C-6), 131.4 (C-2), 131.1 (C-4), 128.8 (C- $\alpha$ ), 124.6 (C-5'), 110.2 (C-3'), 108.2 (C-1'), 65.5 $\left(\mathrm{OCH}_{3}\right), 7.0\left(\mathrm{CH}_{3}\right)$. HRMS m/z: calcd for $\mathrm{C}_{18} \mathrm{H}_{16} \mathrm{BrO}_{5}: 391.0181[\mathrm{M}+\mathrm{H}]^{+}$, found: 391.0145.

\section{3'-Formyl-4',6'-dihydroxy-2'-methoxy-5'-methyl-3,4-benzchalcone}

(1c). $59.5 \%$ yield. Yellow needles, Mp: $106-108^{\circ} \mathrm{C} .{ }^{1} \mathrm{H}-\mathrm{NMR}\left(500 \mathrm{MHz}, \mathrm{CDCl}_{3}\right) \delta: 14.57$ $(1 \mathrm{H}, \mathrm{s}$, chelated-OH-6'), $12.68(1 \mathrm{H}, \mathrm{s}$, chelated-OH-4') $10.06(1 \mathrm{H}, \mathrm{s}, \mathrm{CHO}), 8.16(1 \mathrm{H}$, d, $J=16.0 \mathrm{~Hz}, \mathrm{H}-\beta), 8.02(1 \mathrm{H}, \mathrm{d}, J=16.0 \mathrm{~Hz}, \mathrm{H}-\alpha), 7.93-7.83(4 \mathrm{H}, \mathrm{m}, \mathrm{Ar}-3,4,7,8)$, 7.58-7.57(3H, m, Ar-2, 5,6), 3.94(3H, s, OCH $), 2.13\left(3 \mathrm{H}, \mathrm{s}, \mathrm{CH}_{3}\right) .{ }^{13} \mathrm{C}-\mathrm{NMR}(125$

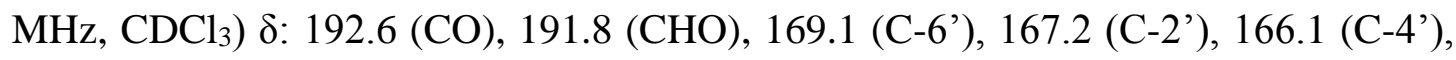
145.1 (C- $\beta$ ), 133.4 (C-8a), 133.1 (C-1), 131.1 (C-4a), 130.9 (C-4), 129.0 (C-7), 128.2 (C-3), 127.9 (C-8), 126.9 (C- $\alpha$ ), 126.7 (C-5), 125.6 (C-6), 123.6 (C-2), 109.4 (C-5'), 
108.6 (C-3'), $91.6\left(\mathrm{C}^{\prime} 1^{\prime}\right), 66.3\left(\mathrm{OCH}_{3}\right), 7.3\left(\mathrm{CH}_{3}\right)$. HRMS m/z: calcd for $\mathrm{C}_{22} \mathrm{H}_{17} \mathrm{O}_{5}$ : 361.1076[M - H $]^{+}$, found: 361.1099.

3'-Formyl-4',6'-dihydroxy-2'-methoxy-5'-methyl-2-fluorochalcone (1d). 57\% yield. Yellow needles, Mp: $103-104{ }^{\circ} \mathrm{C} .{ }^{1} \mathrm{H}-\mathrm{NMR}\left(500 \mathrm{MHz}, \mathrm{CDCl}_{3}\right) \delta: 14.01(1 \mathrm{H}, \mathrm{s}$, chelated-OH-6'), $12.67(1 \mathrm{H}, \mathrm{s}$, chelated-OH-4'), $10.16(1 \mathrm{H}, \mathrm{s}, \mathrm{CHO}), 8.05(1 \mathrm{H}, \mathrm{d}, J=$ $16.0 \mathrm{~Hz}, \mathrm{H}-\beta), 8.01(1 \mathrm{H}, \mathrm{d}, J=16.0 \mathrm{~Hz}, \mathrm{H}-\alpha), 7.68(1 \mathrm{H}, \mathrm{m}, \mathrm{H}-4), 7.45$ ( $1 \mathrm{H}, \mathrm{m}, \mathrm{H}-6)$, 7.26-7.17 (2H, m, H-3, 5), $3.93\left(3 \mathrm{H}, \mathrm{s}, \mathrm{OCH}_{3}\right), 2.11\left(3 \mathrm{H}, \mathrm{s}, \mathrm{CH}_{3}\right) .{ }^{13} \mathrm{C}-\mathrm{NMR}(125$ $\mathrm{MHz}, \mathrm{CDCl}_{3}$ ) $\delta: 192.8$ (CO), 192.5 (CHO), 171.1 (C-6'), 168.8 (C-2'), 168.6 (C-4'), 161.9 (C-2),137.5 (C- $\beta$ ), 132.4 (C-4), 130.9 (C-6), 129.8 (C-5), 128.8 (C-1), 127.1 (C-3), 124.7 (C- $\alpha), 116.4\left(\mathrm{C}^{-5}{ }^{\prime}\right), 110.1$ (C-3'), $109.5\left(\mathrm{C}-1^{\prime}\right), 66.3\left(\mathrm{OCH}_{3}\right), 6.7\left(\mathrm{CH}_{3}\right)$. HRMS m/z: calcd for $\mathrm{C}_{18} \mathrm{H}_{15} \mathrm{FO}_{5} \mathrm{Na}: 353.0801[\mathrm{M}+\mathrm{Na}]^{+}$, found: 353.0828 .

\section{3'-Formyl-4',6'-dihydroxy-2'-methoxy-5'-methyl-2-trifluoromethylchalcone}

(1e). $40.7 \%$ yield. Yellow needles, Mp: $110-112^{\circ} \mathrm{C} .{ }^{1} \mathrm{H}-\mathrm{NMR}\left(500 \mathrm{MHz}, \mathrm{CDCl}_{3}\right) \delta$ : 14.96 (1H, s, chelated-OH-6'), 14.57 (1H, s, chelated-OH-4'), 10.06 (1H, s, CHO), $8.54(1 \mathrm{H}, \mathrm{d}, J=16.0 \mathrm{~Hz}, \mathrm{H}-\beta), 8.46(1 \mathrm{H}, \mathrm{d}, J=16.0 \mathrm{~Hz}, \mathrm{H}-\alpha), 7.92(1 \mathrm{H}, \mathrm{m}, \mathrm{H}-3)$, $7.83(1 \mathrm{H}, \mathrm{m}, \mathrm{H}-5), 7.74(2 \mathrm{H}, \mathrm{m}, \mathrm{H}-5,6), 3.95\left(3 \mathrm{H}, \mathrm{s}, \mathrm{OCH}_{3}\right), 2.75\left(3 \mathrm{H}, \mathrm{s}, \mathrm{CH}_{3}\right)$. ${ }^{13} \mathrm{C}-\mathrm{NMR}\left(125 \mathrm{MHz}, \mathrm{CDCl}_{3}\right.$ ) $\delta: 203.9$ (CO), 191.8 (CHO), 174.0 (C-6’), 169.9 (C-2'), 167.2 (C-4'), 137.9 (C-ß), 129.9 (C-1), 129.9 (C-5), 125.0 (C-4), 121.2 (C-6), 121.0 (C- $\alpha), 107.2$ (C-3), 105.9 (C-2), $104.9\left(\mathrm{CF}_{3}\right), 102.4$ (C-5'), 102.3 (C-3'), 91.6 (C-1'), $56.3\left(\mathrm{OCH}_{3}\right), 7.3\left(\mathrm{CH}_{3}\right)$. HRMS m/z: calcd for $\mathrm{C}_{19} \mathrm{H}_{14} \mathrm{~F}_{3} \mathrm{O}_{5}: 379.0793[\mathrm{M}-\mathrm{H}]^{+}$, found: 
379.0832 .

\section{Cytotoxic Activity Assay.}

Table S1. Activities against human cancer cell lines

\begin{tabular}{|c|c|c|c|c|c|c|}
\hline & \multicolumn{6}{|c|}{$\mathrm{IC}_{50}(\mu \mathrm{M})$} \\
\hline Compounds & HCT-8 & A549 & GNM & DU-145 & HL-60 & HUVEC \\
\hline 1 & $>50$ & $>50$ & $>50$ & $>50$ & $>50$ & $>50$ \\
\hline $1 b$ & $17.9 \pm 0.6$ & $15.5 \pm 0.8$ & $18.1 \pm 1.0$ & $20.2 \pm 1.6$ & $10.8 \pm 0.9$ & $16.3 \pm 1.2$ \\
\hline $1 \mathrm{c}$ & $>50$ & $>50$ & $>50$ & $>50$ & $>50$ & $>50$ \\
\hline $1 d$ & $>50$ & $>50$ & $>50$ & $>50$ & $>50$ & $>50$ \\
\hline $1 \mathrm{e}$ & $>50$ & $>50$ & $>50$ & $>50$ & $>50$ & $>50$ \\
\hline \multicolumn{7}{|l|}{ Paclitaxel } \\
\hline$(\mathrm{nM})$ & $>50$ & $5.1 \pm 0.3$ & $16.0 \pm 1.2$ & $9.2 \pm 0.7$ & $>50$ & $6.6 \pm 0.5$ \\
\hline
\end{tabular}

\section{REFERENCES}

1. Umehara, K.; Singh, I. P.; Etoh, H.; Takasaki, M.; Konoshima, T. Phytochemistry. 1998, 49, 1699-1704.

2. Sato, S.; Obara, H.; Onodera, J.; Endo, A.; Matsuba, S. Bull. Chem. Soc. Jpn. 1992, 65, 452-457.

3. Nakagawa-Goto, K.; Lee, K. H. Tetrahedron. lett. 2006, 47, 8263-8266.

4. $\quad$ Ye, C. L.; Lu, Y. H.; Wei, D. Z. Phytochemistry. 2004, 65, 445-447. 


\section{Generic Display Report}

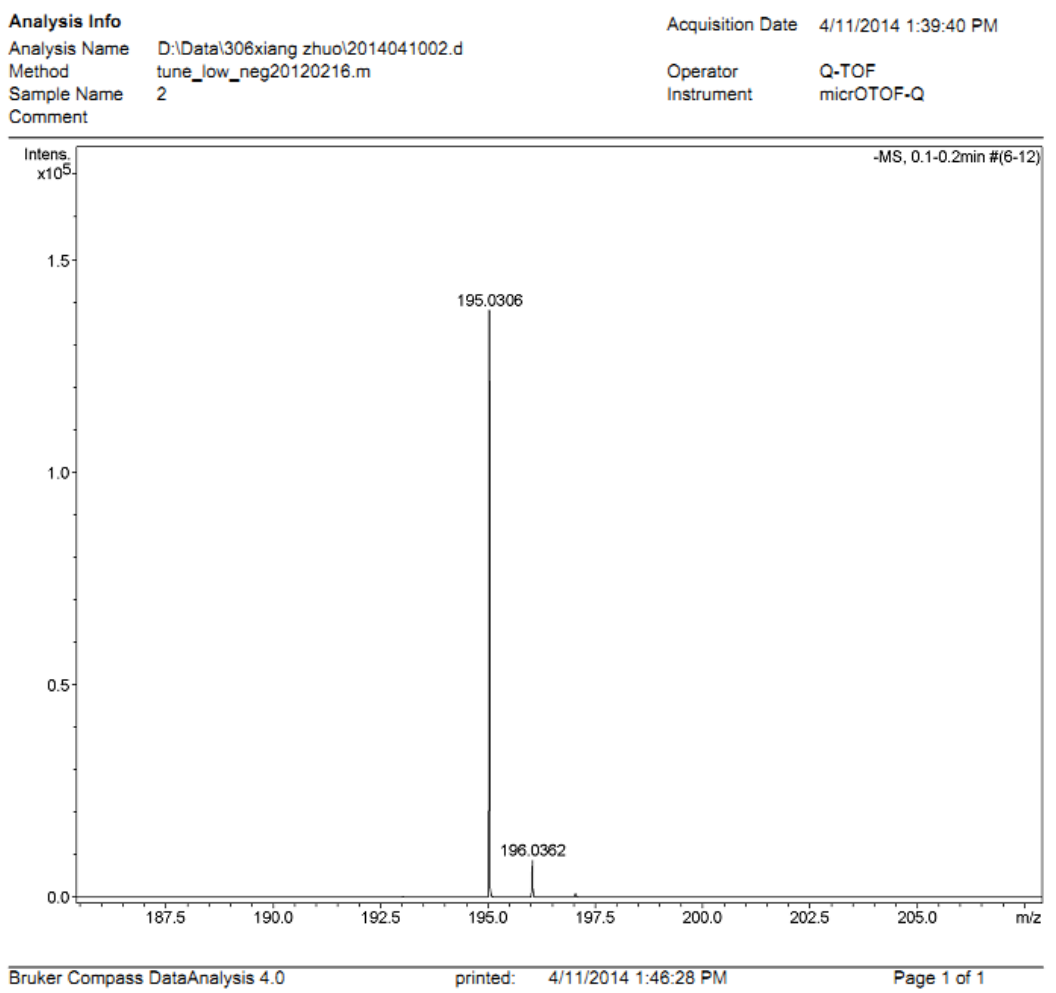

HRMS spectra of compound 7

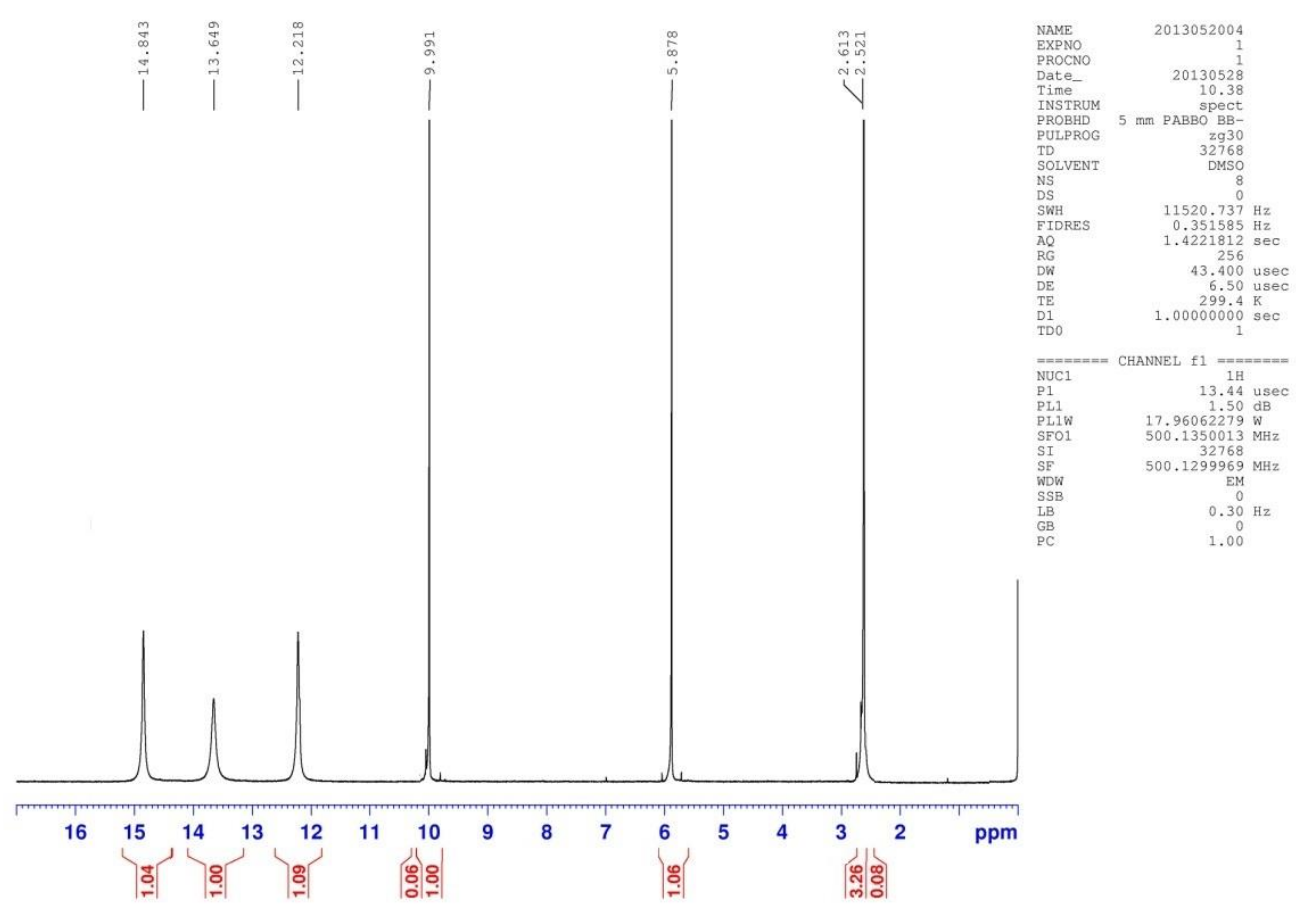

${ }^{1} \mathrm{H}$ NMR spectra of compound 7 


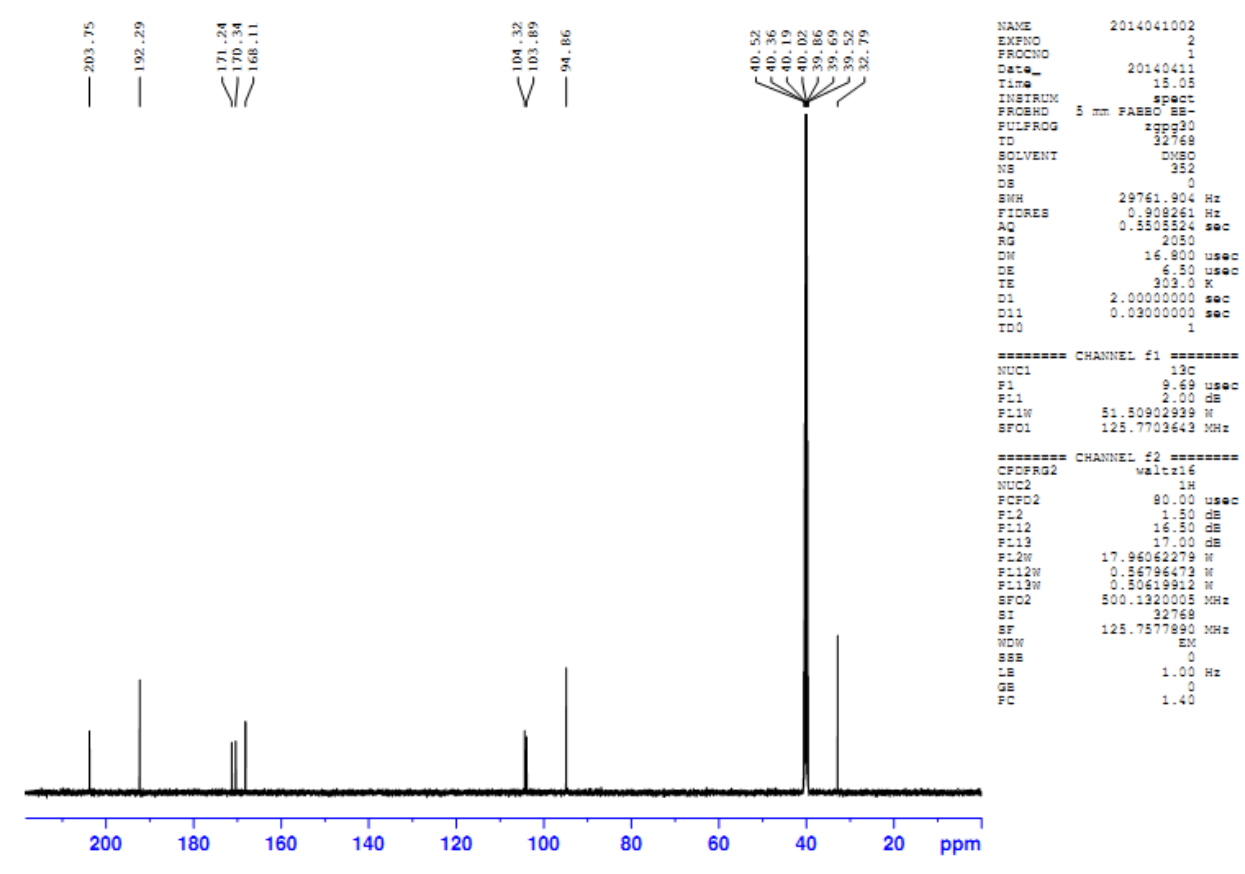

${ }^{13} \mathrm{C}$ NMR spectra of compound 7

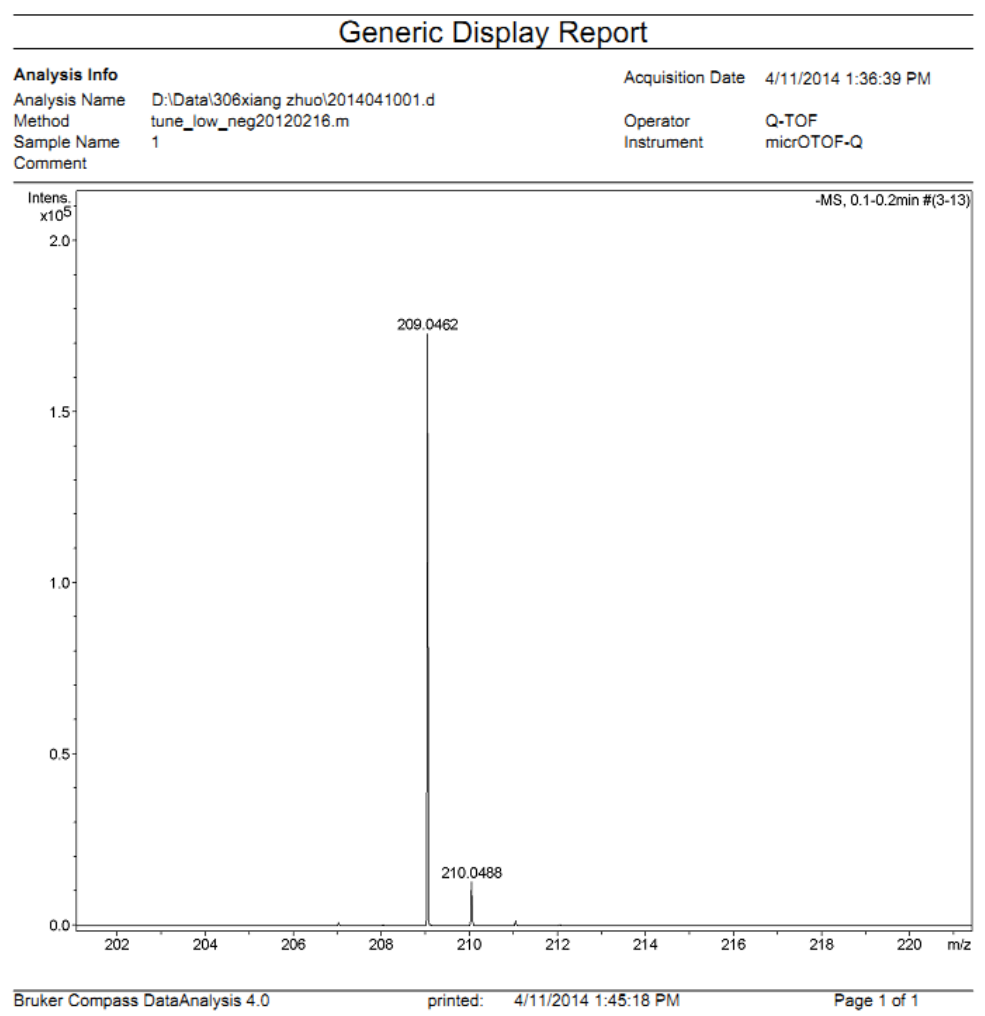

HRMS spectra of compound 8 


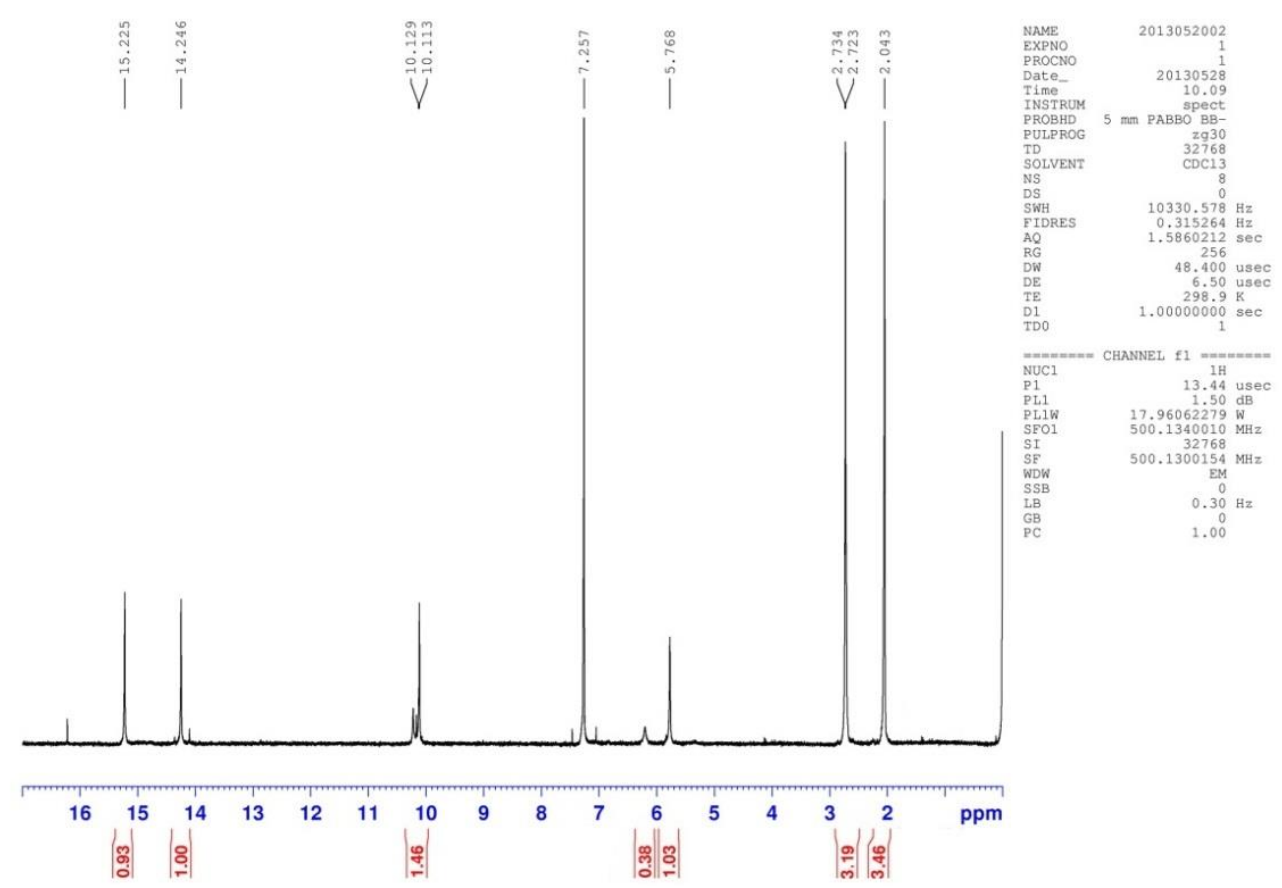

${ }^{1}$ H NMR spectra of compound 8

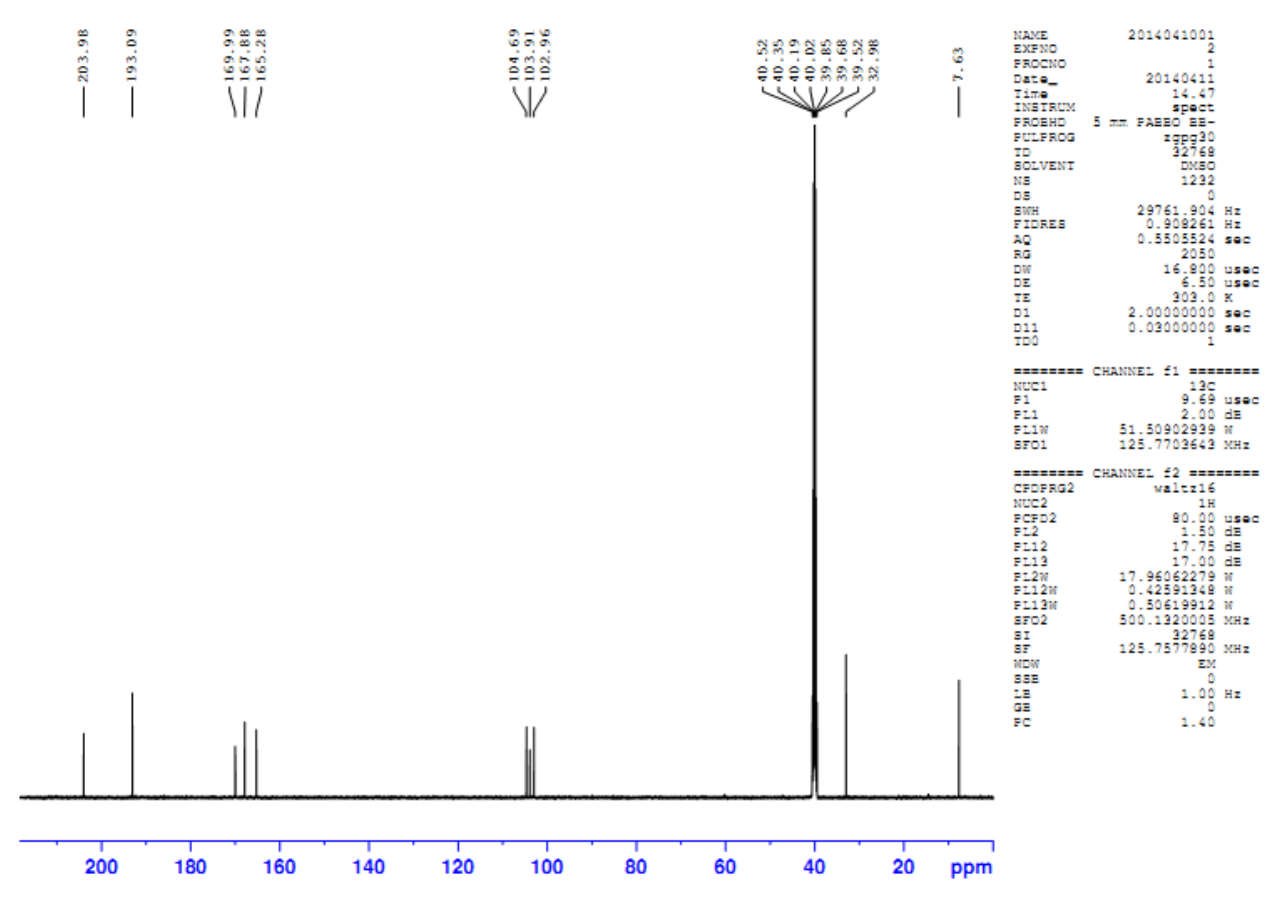

${ }^{13} \mathrm{C}$ NMR spectra of compound 8 


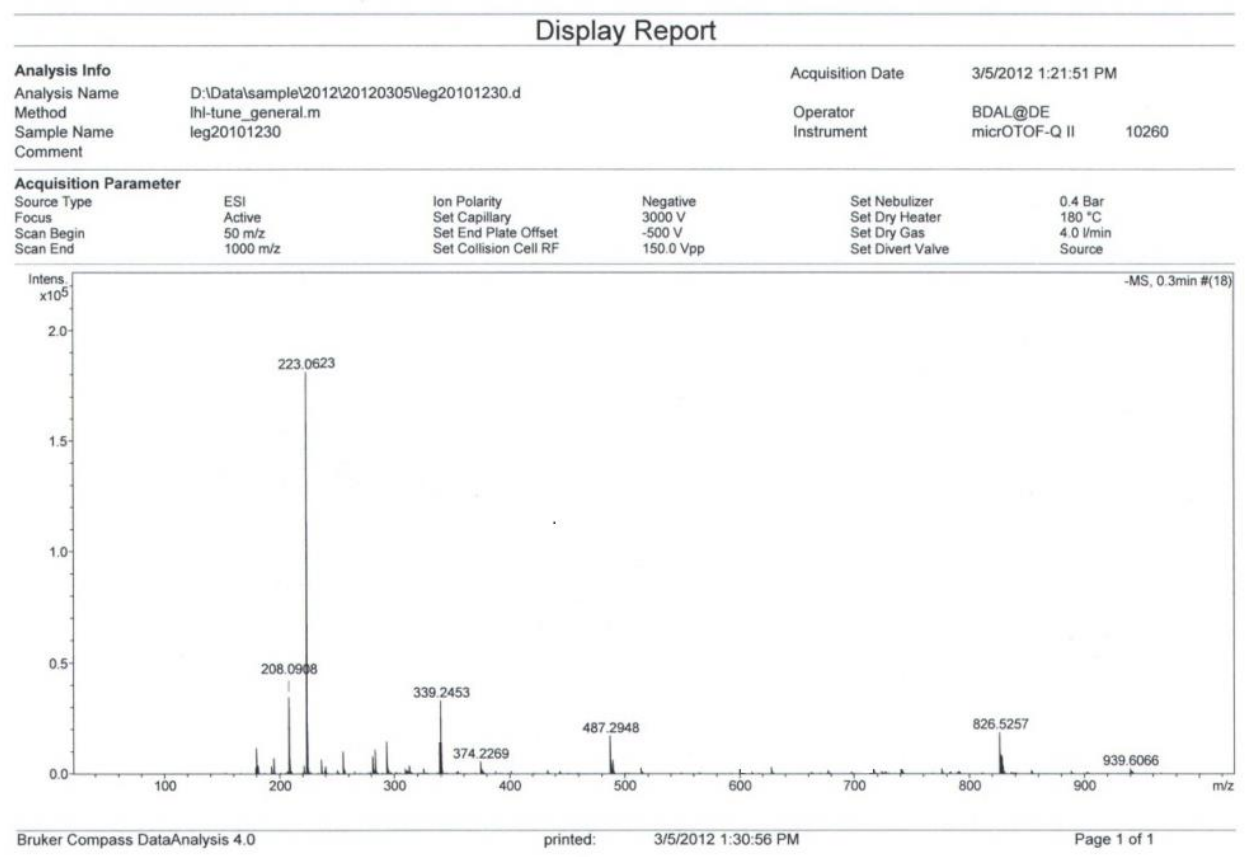

HRMS spectra of compound 2

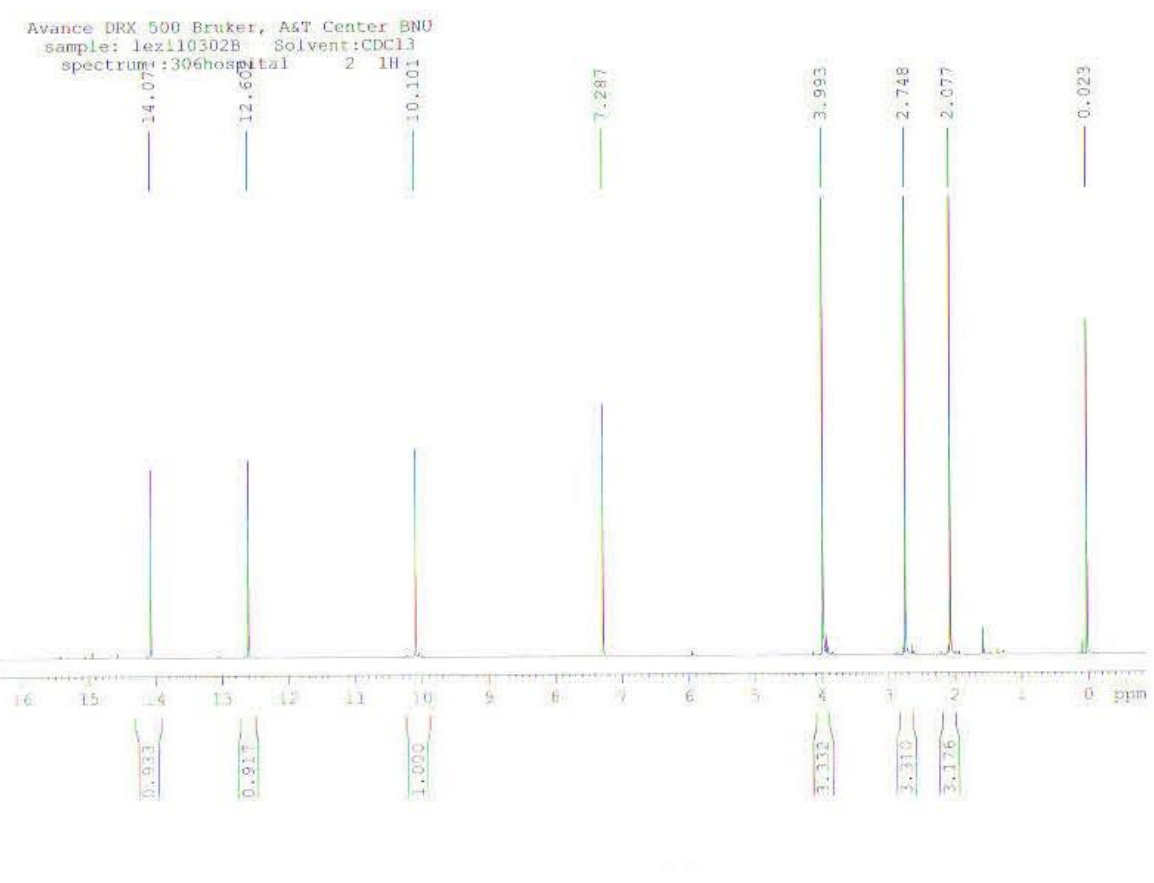

${ }^{1} \mathrm{H}$ NMR spectra of compound 2 


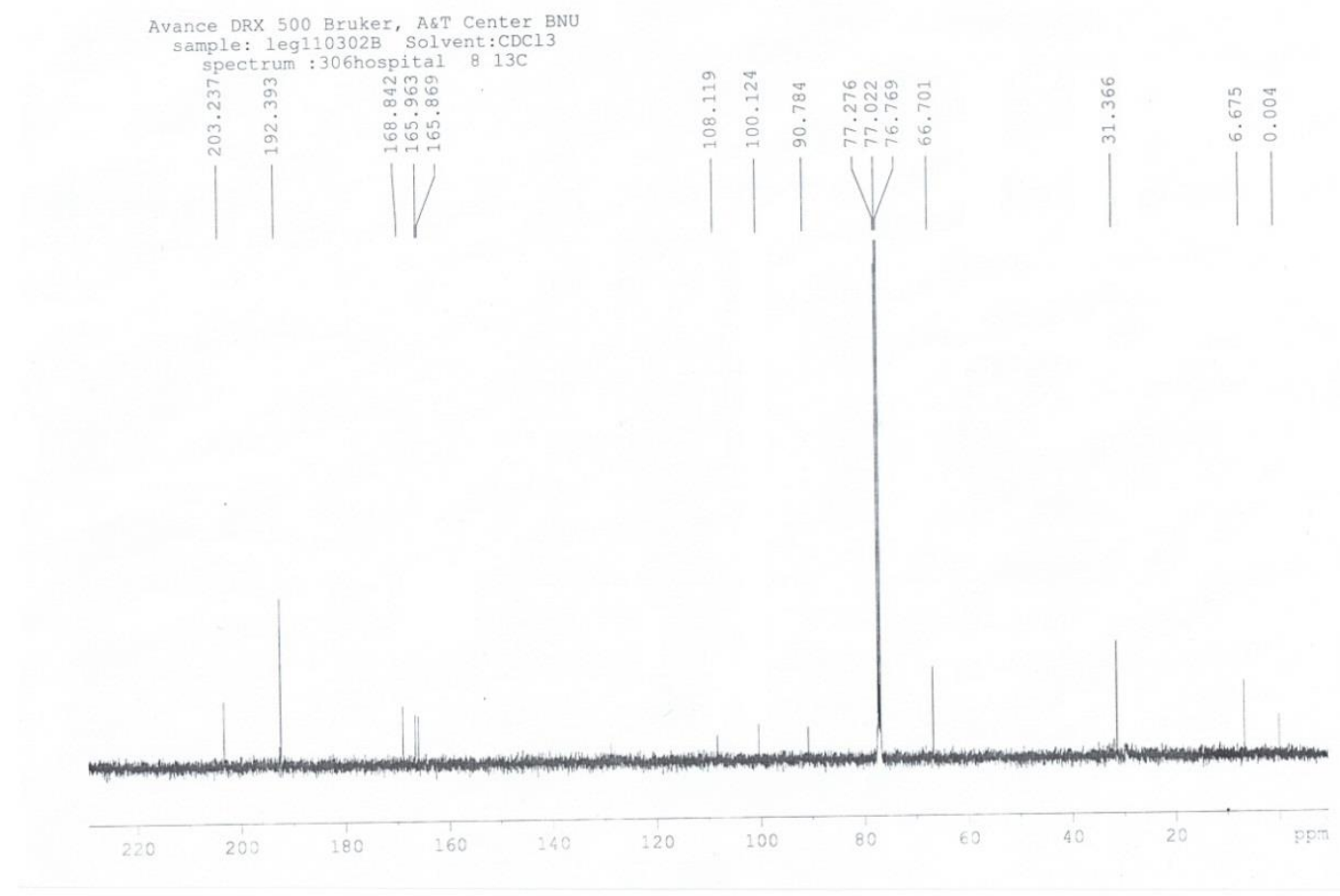

${ }^{13} \mathrm{C}$ NMR spectra of compound 2

lez110302B NOE

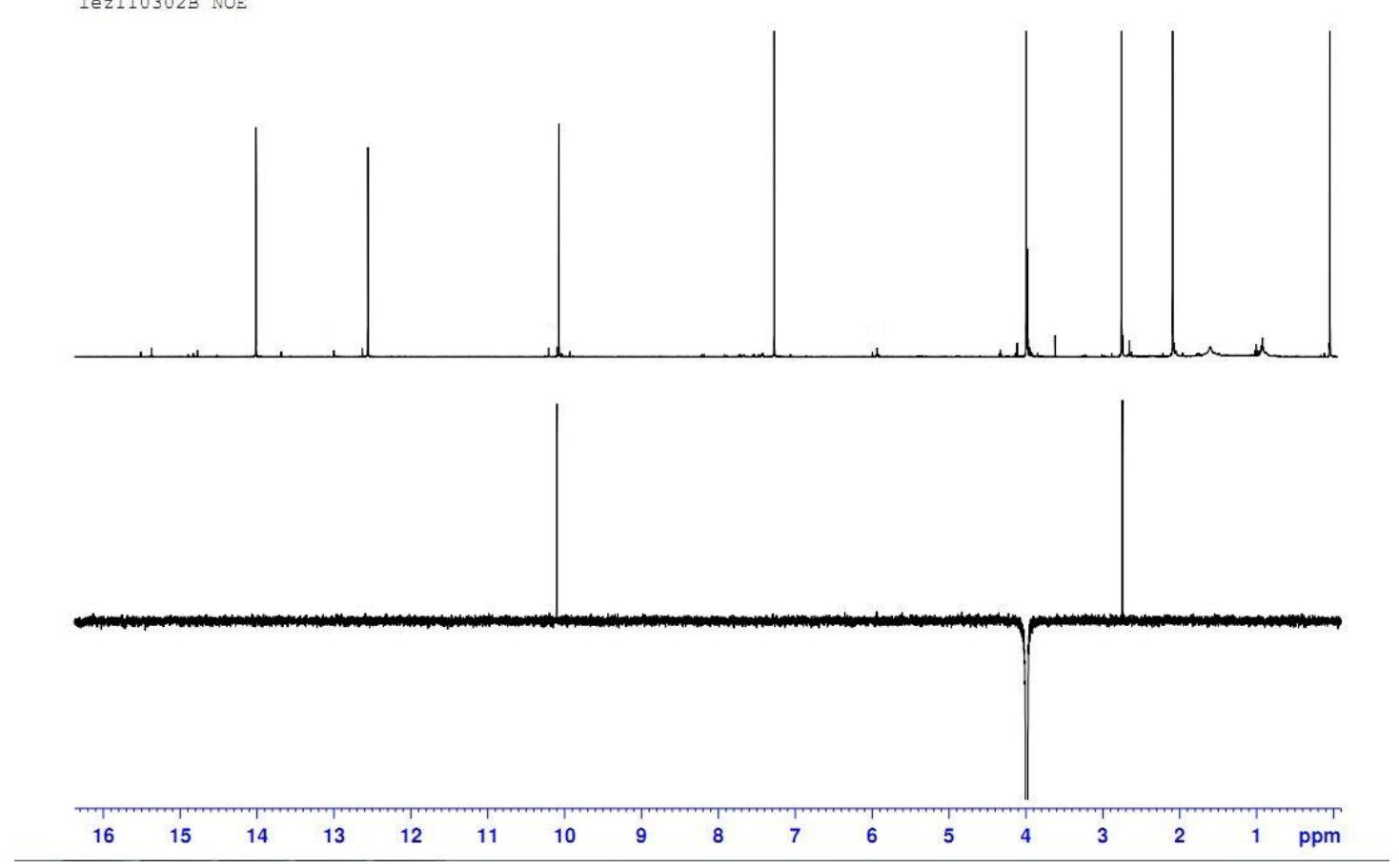

NOE spectra of compound 2 


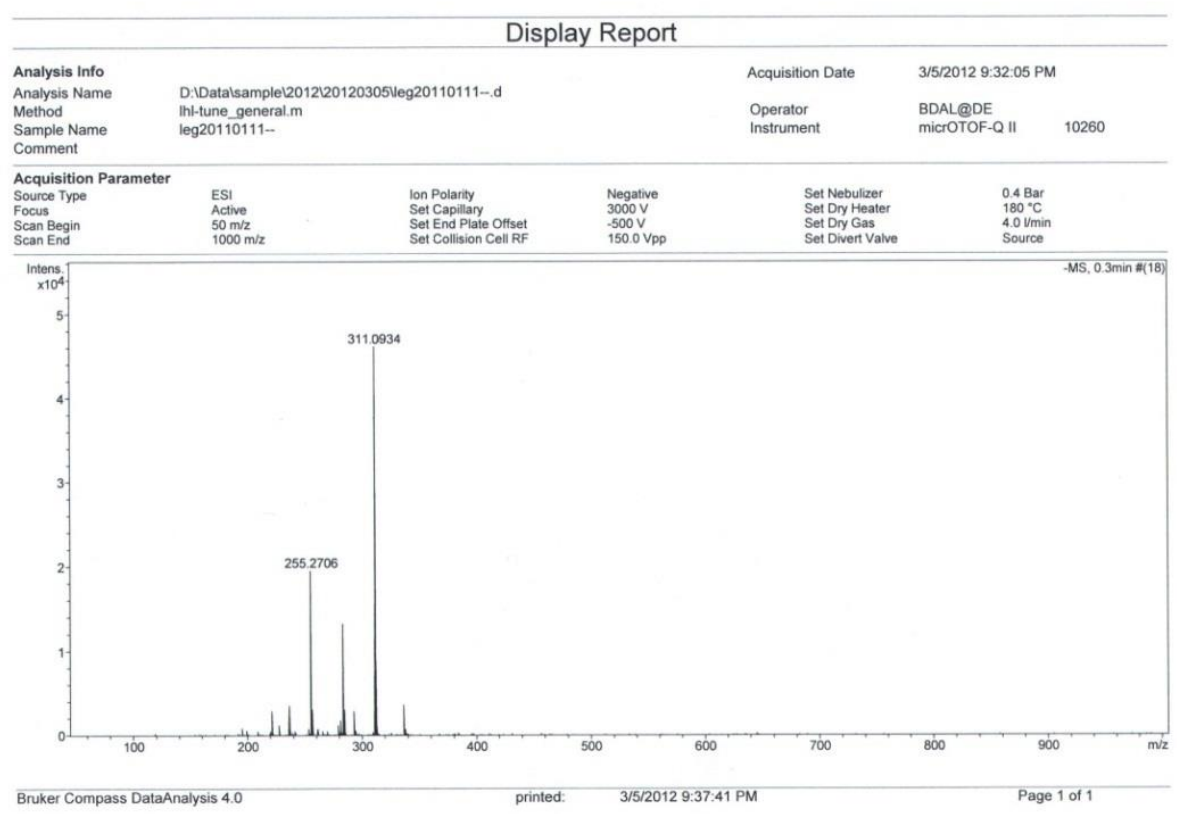

HRMS spectra of compound 1

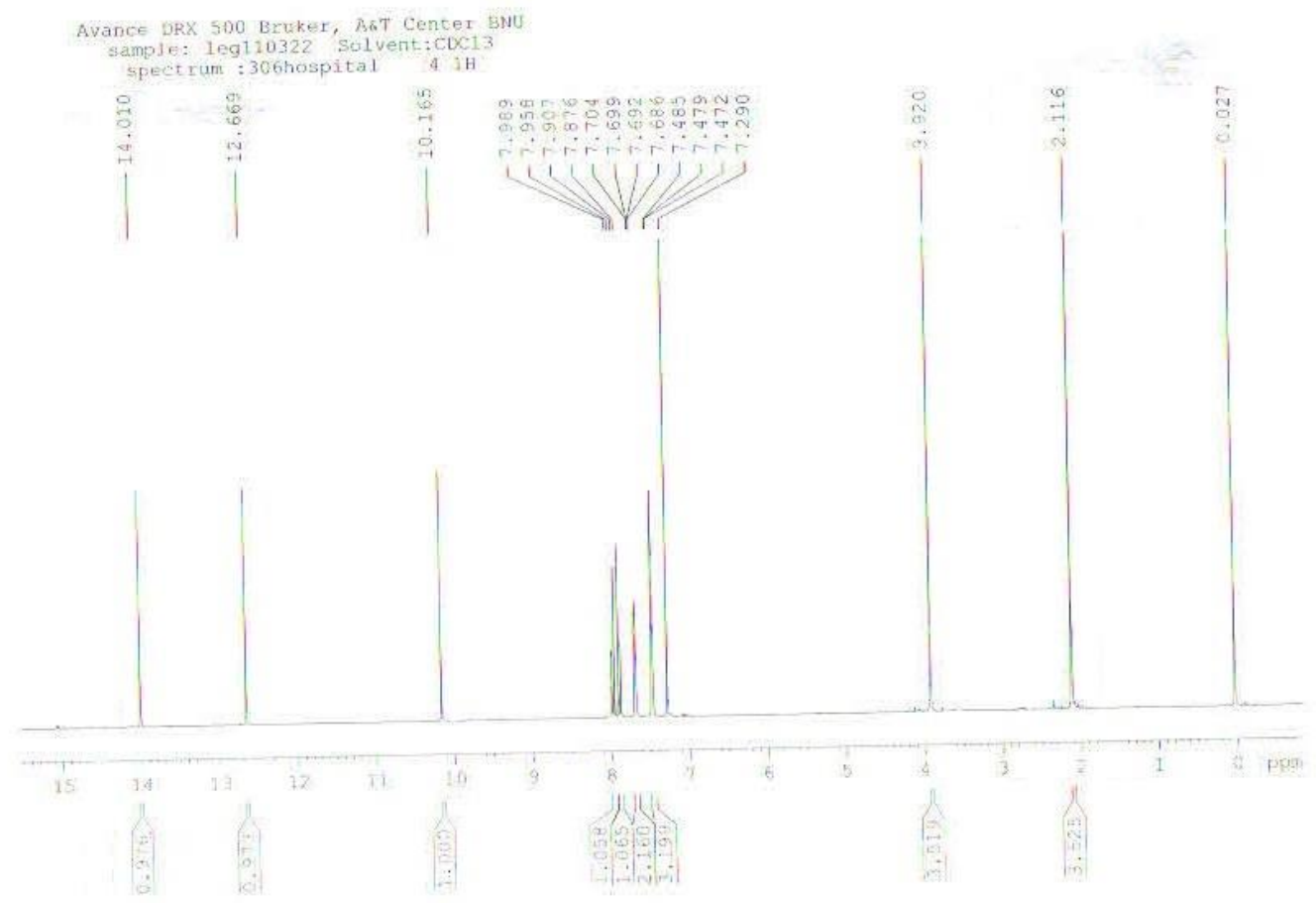

${ }^{1} \mathrm{H}$ NMR spectra of compound 1 


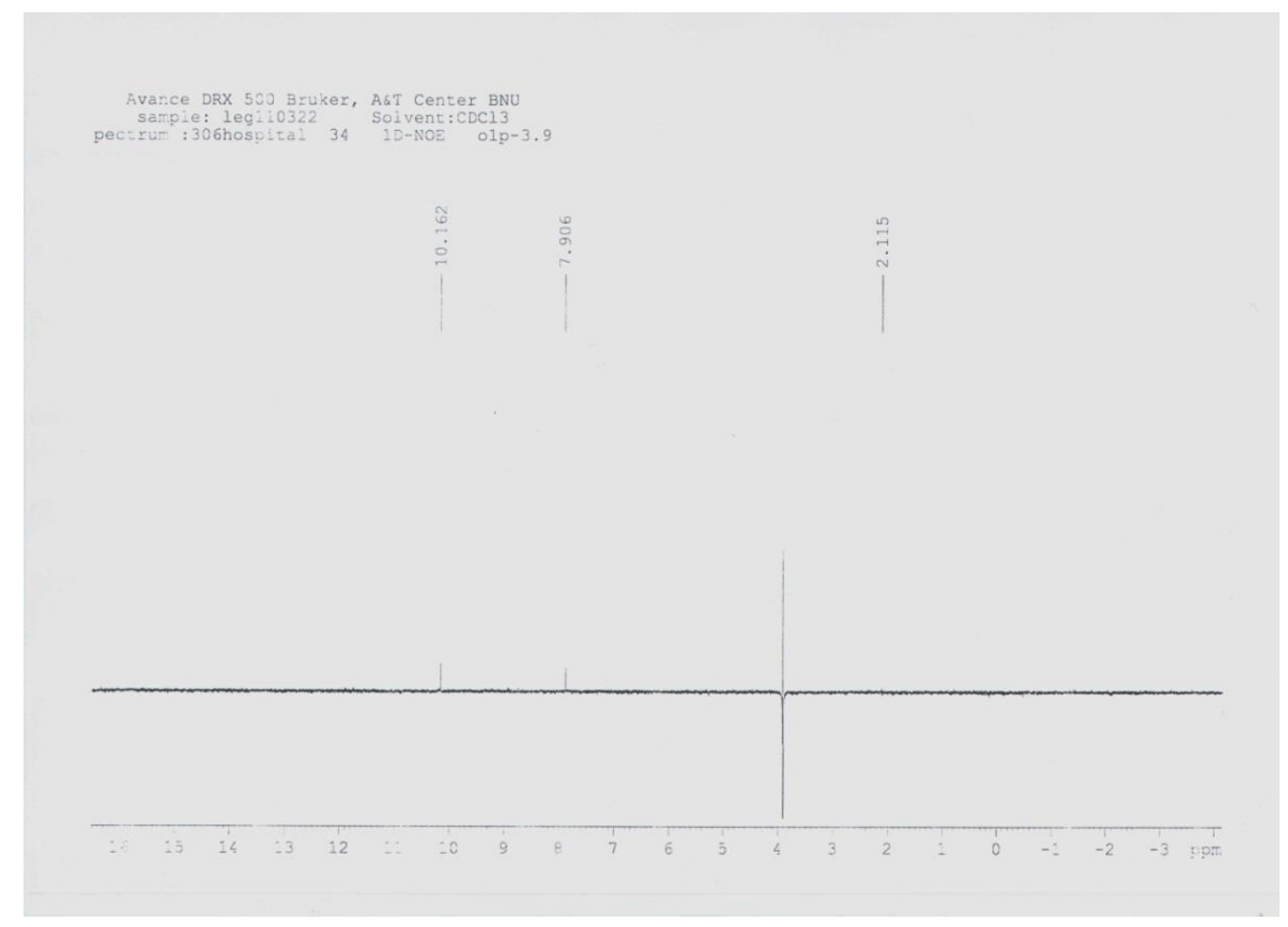

NOE spectra of compound 1

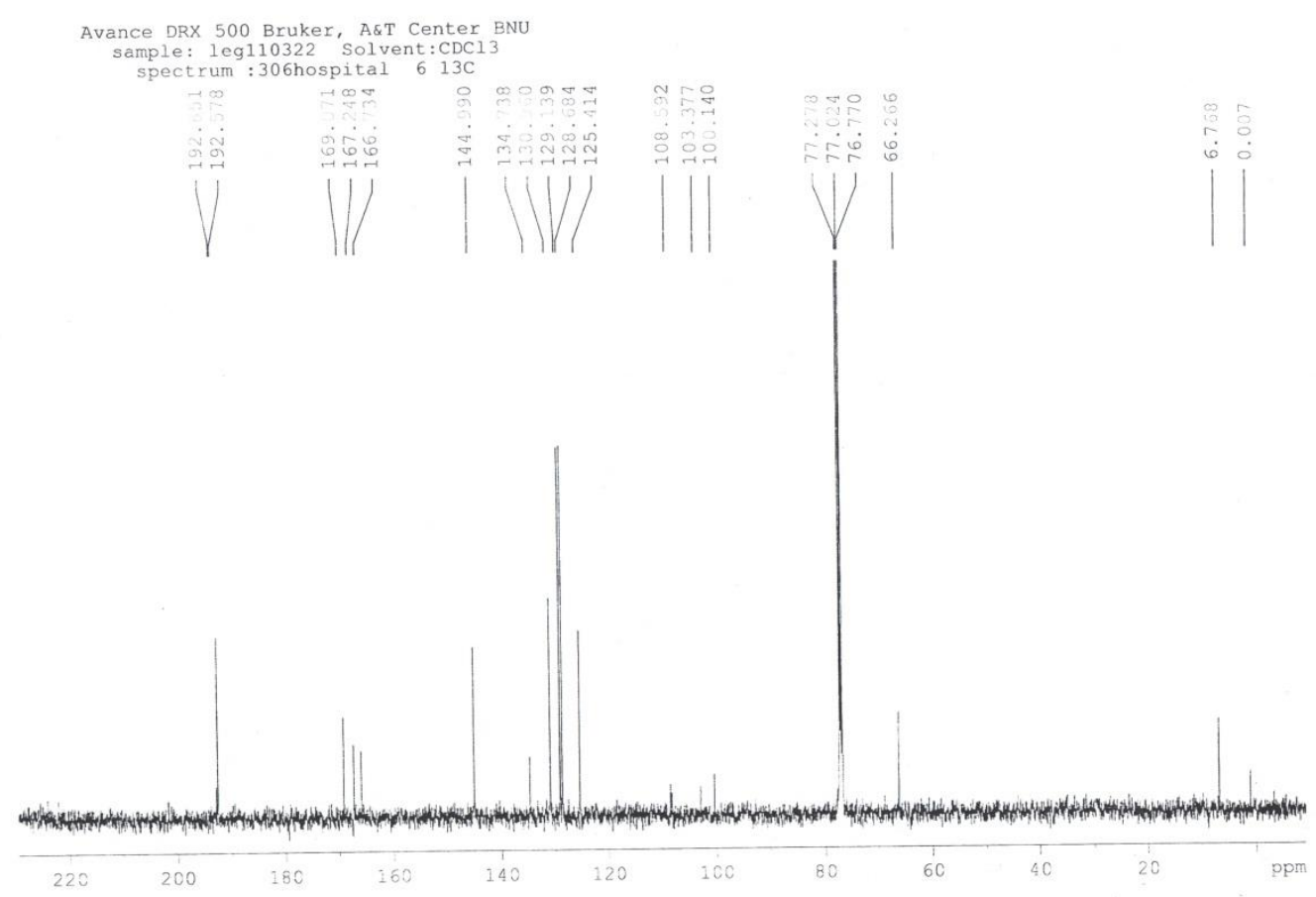

${ }^{13} \mathrm{C}$ NMR spectra of compound 1 


\section{Mass Spectrum SmartFormula Report}

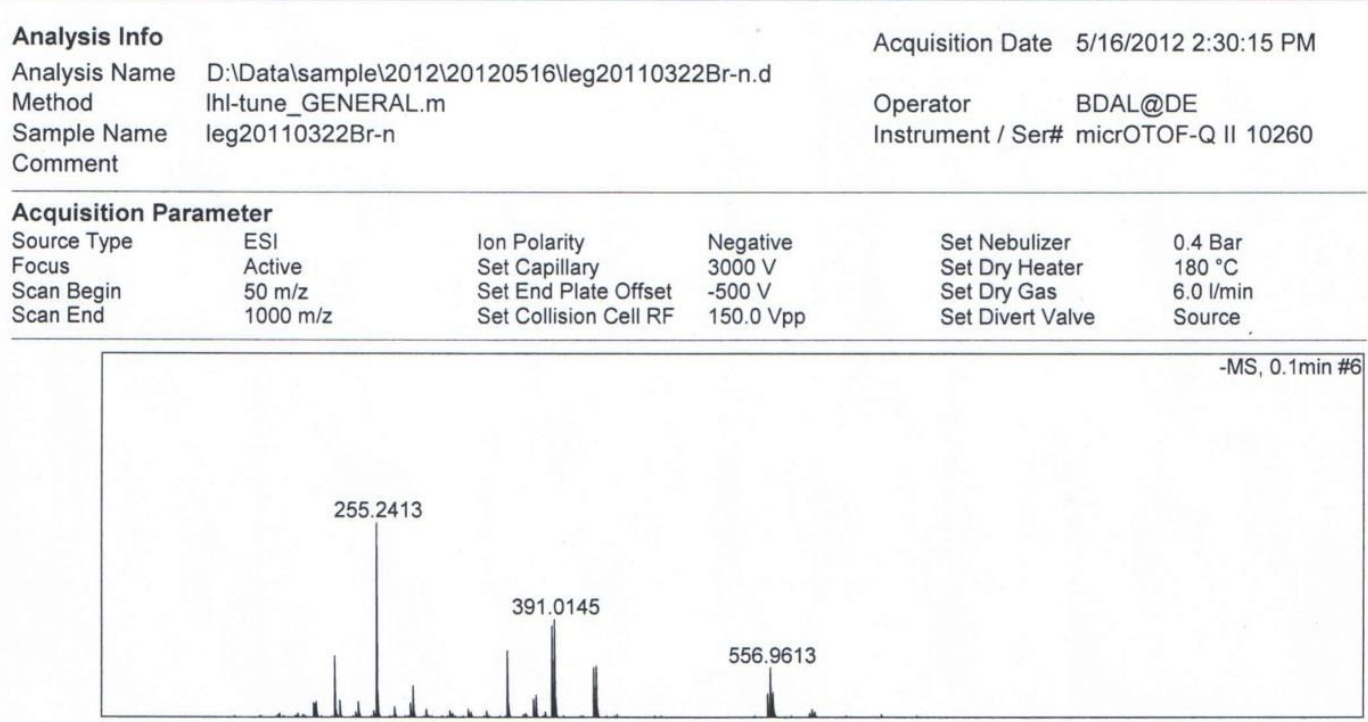

HRMS spectra of compound 1b

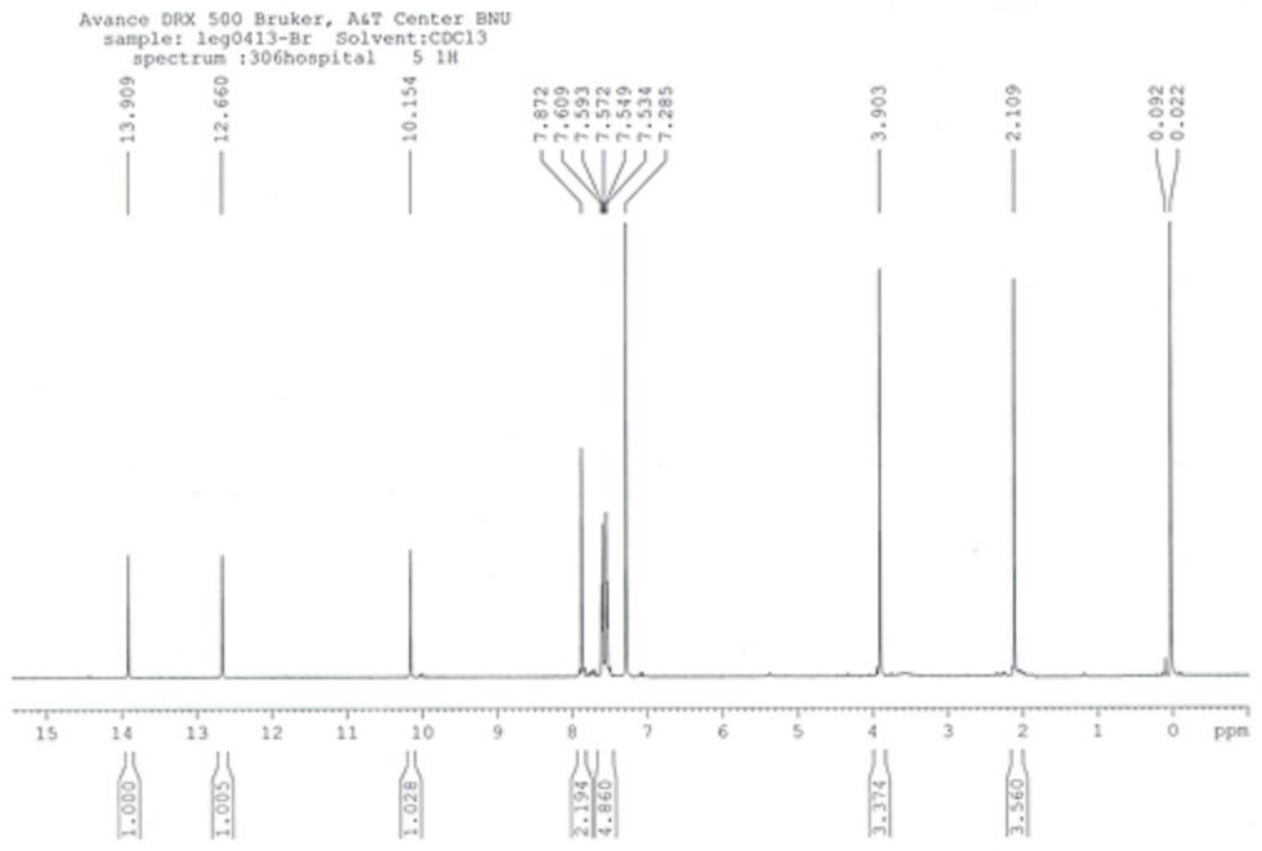

${ }^{1} \mathrm{H}$ NMR spectra of compound $1 \mathrm{~b}$ 


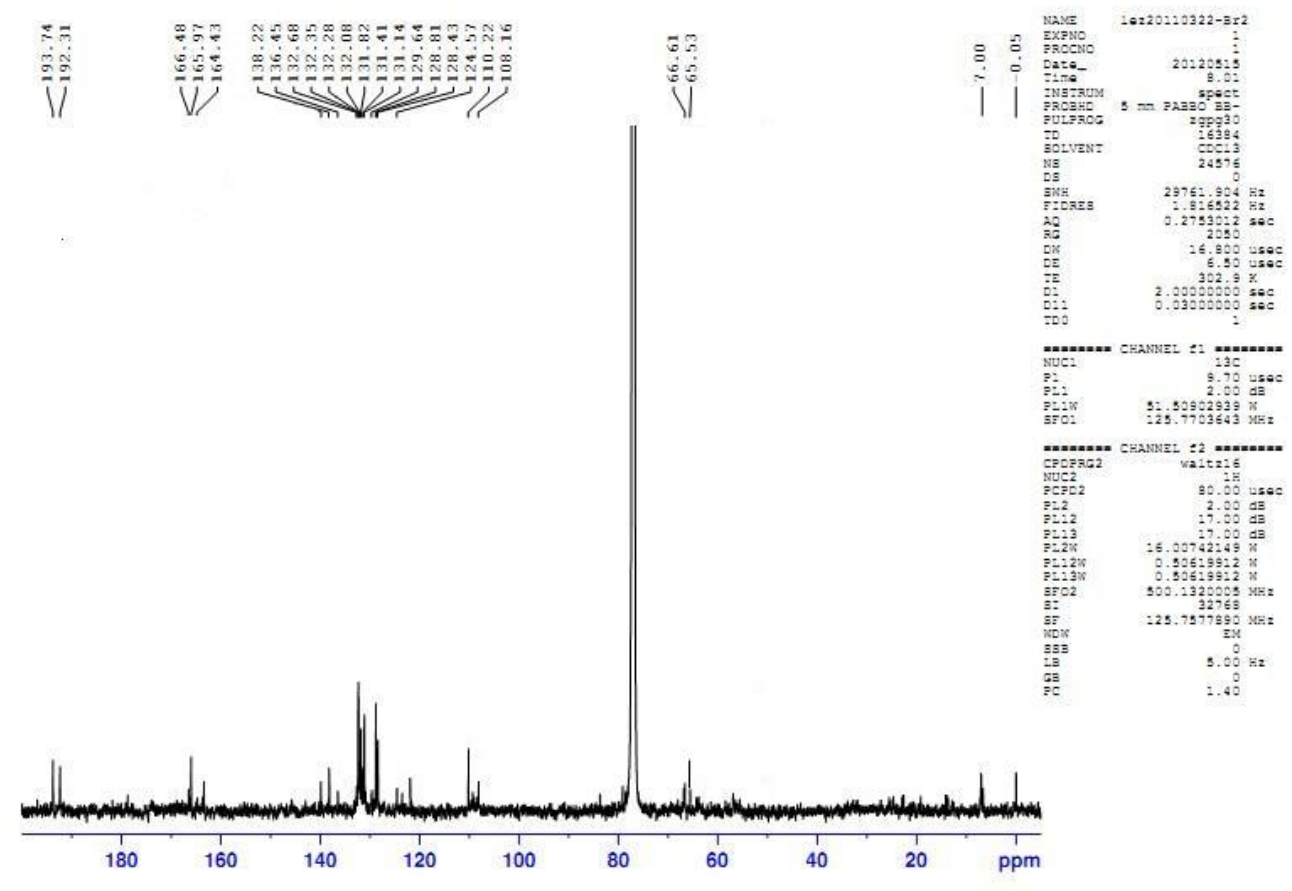

${ }^{13} \mathrm{C}$ NMR spectra of compound $1 \mathrm{~b}$

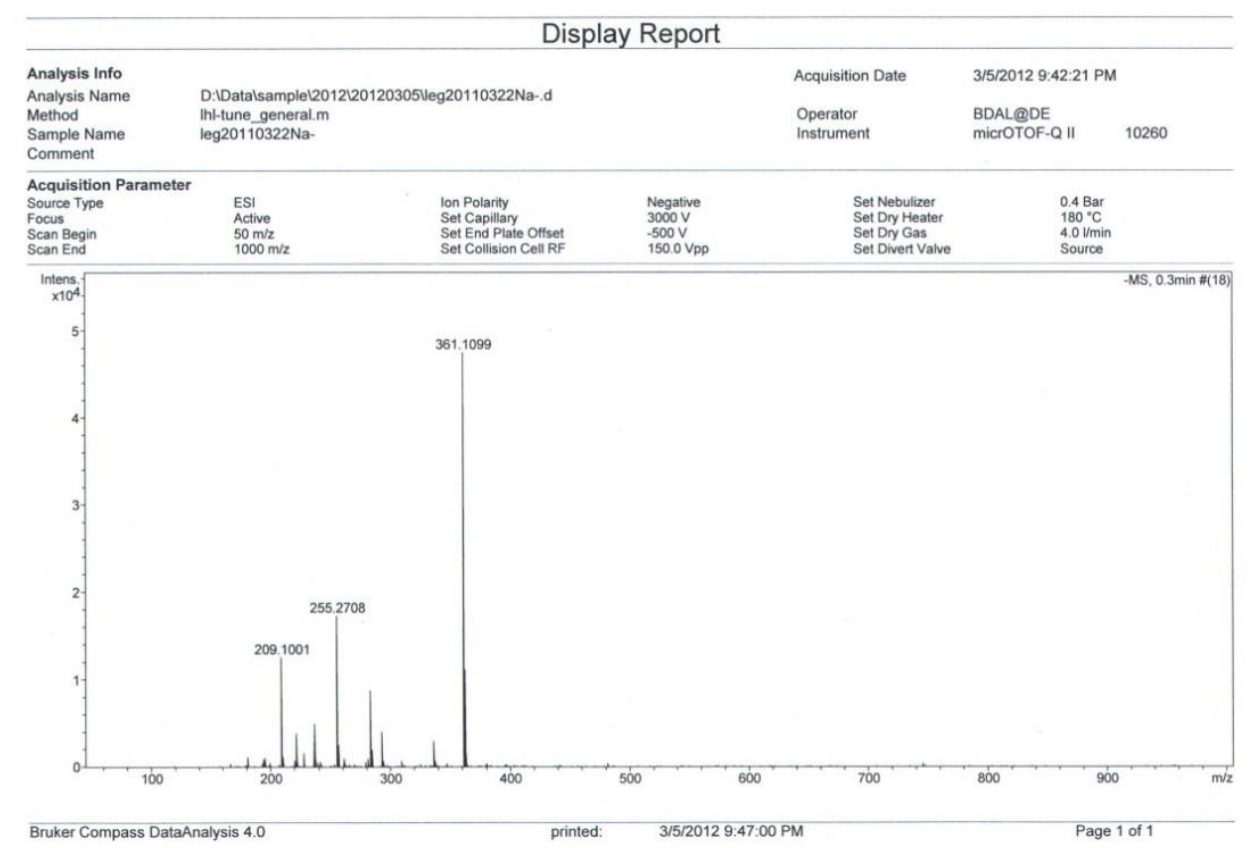

HRMS spectra of compound 1c 


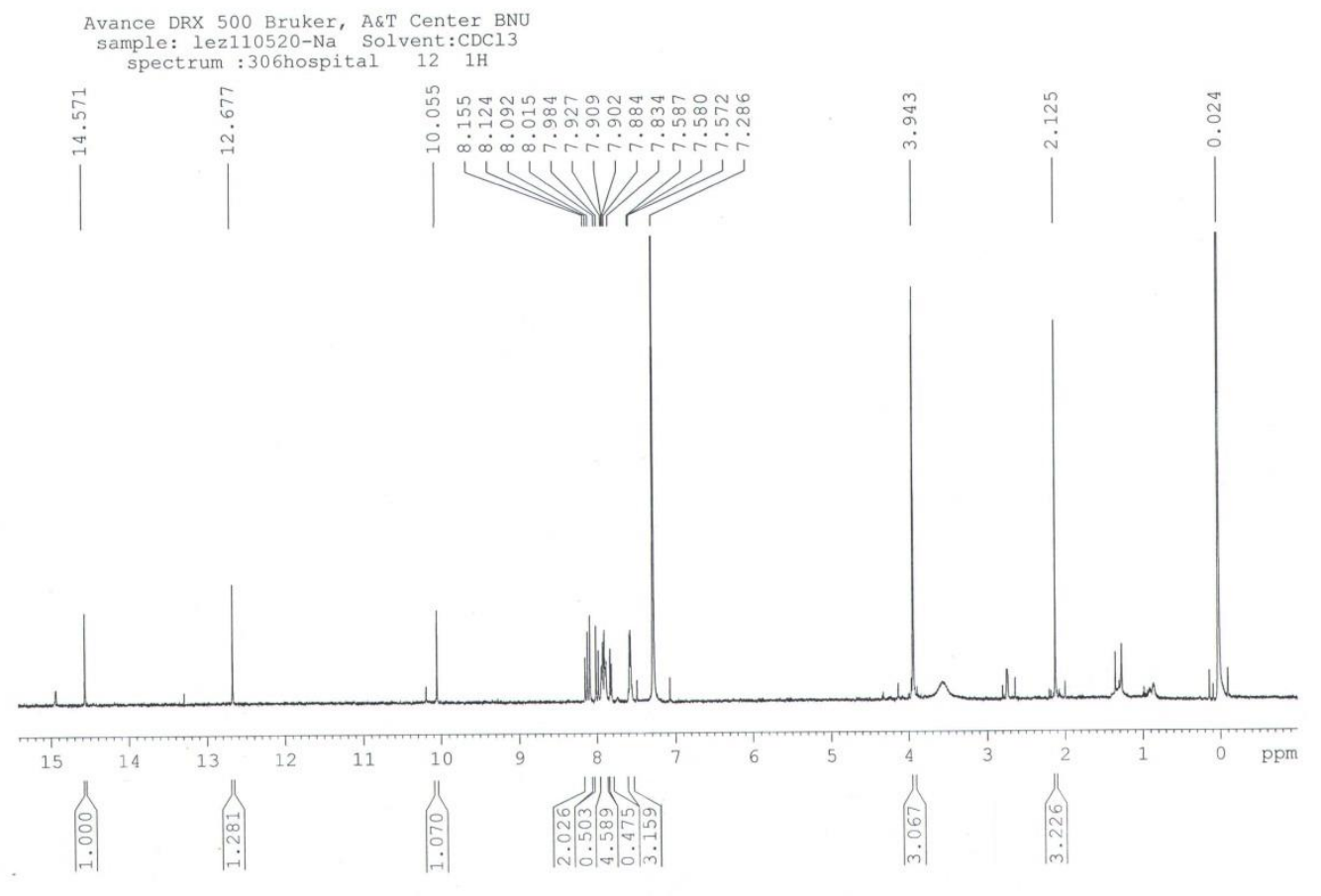

${ }^{1} \mathrm{H}$ NMR spectra of compound 1c

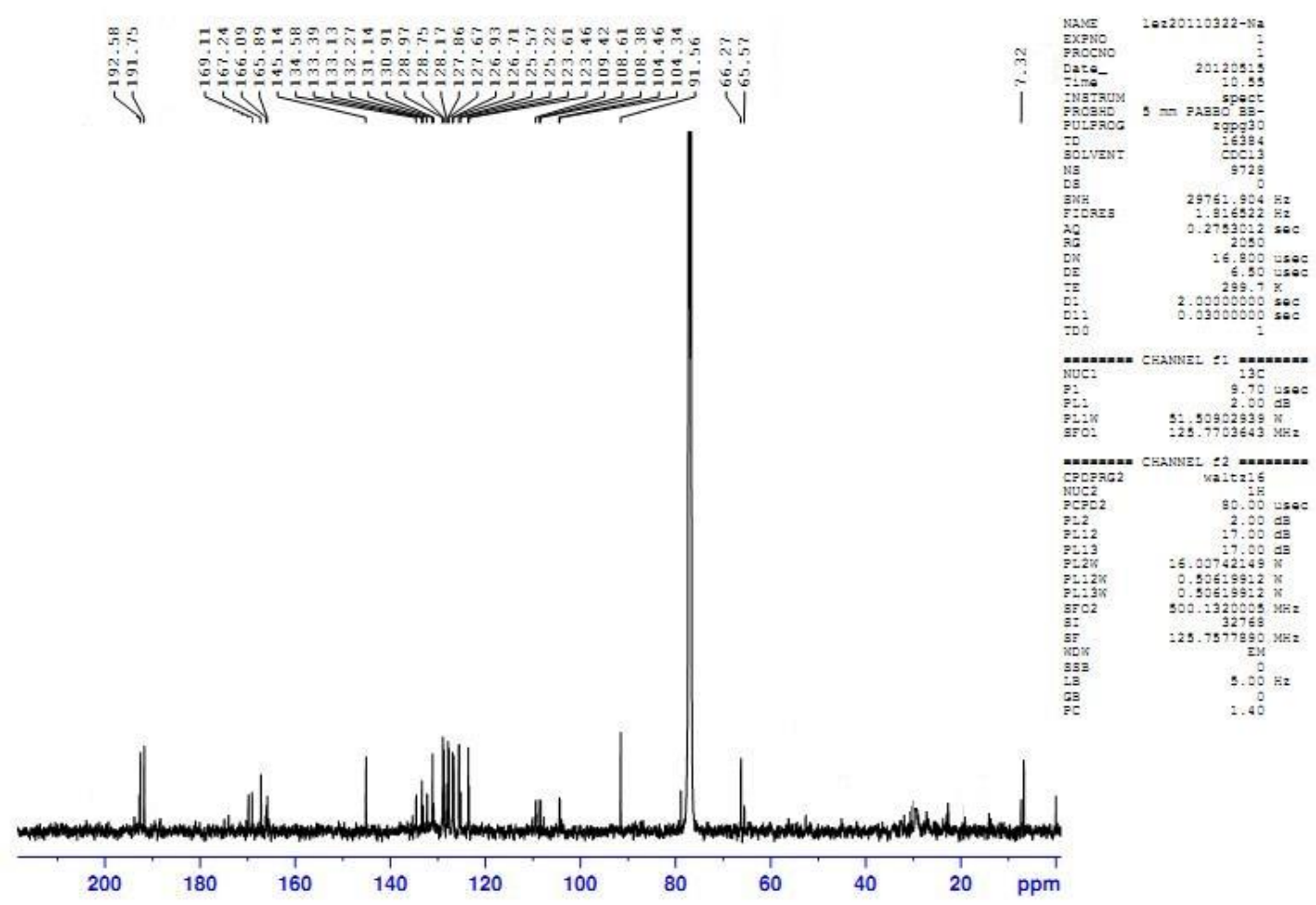

${ }^{13} \mathrm{C}$ NMR spectra of compound $1 \mathrm{c}$ 


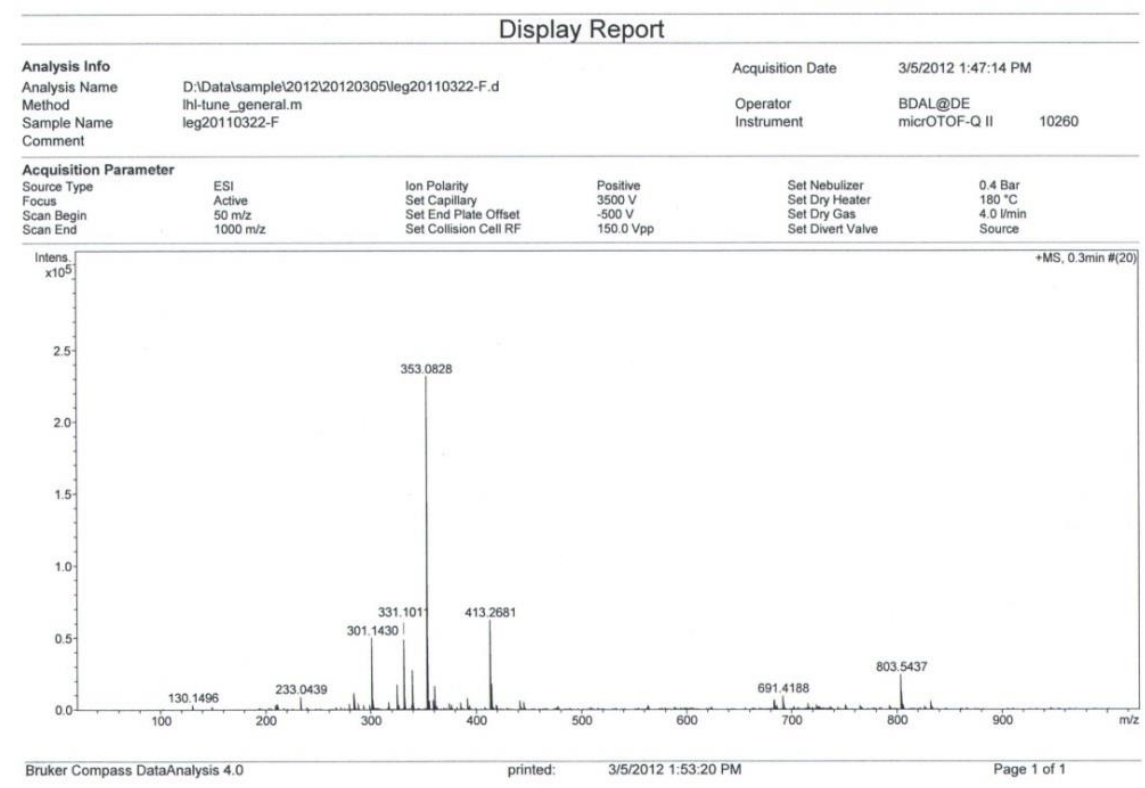

HRMS spectra of compound 1d

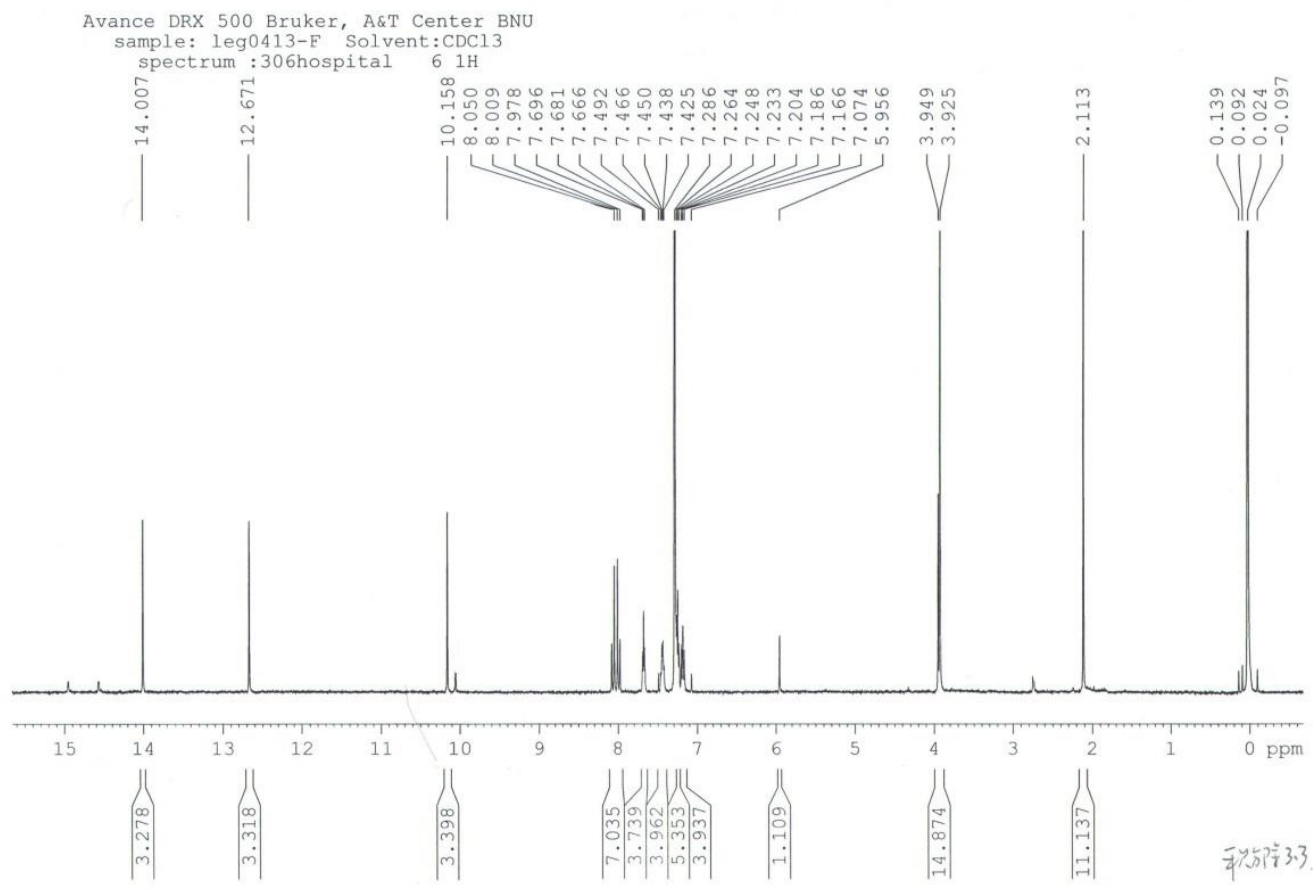

${ }^{1} \mathrm{H}$ NMR spectra of compound 1d 


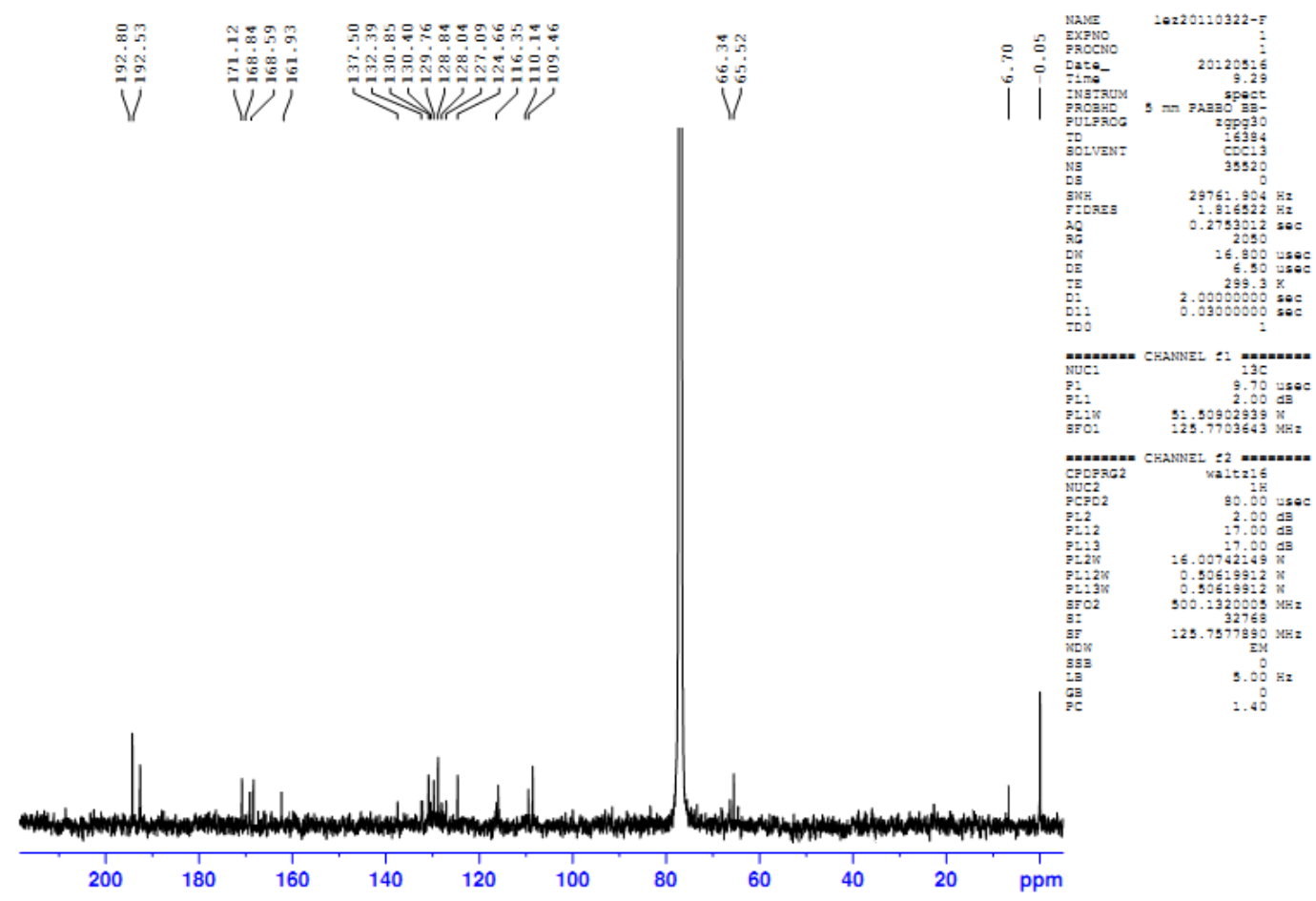

${ }^{13} \mathrm{C}$ NMR spectra of compound $1 \mathrm{~d}$

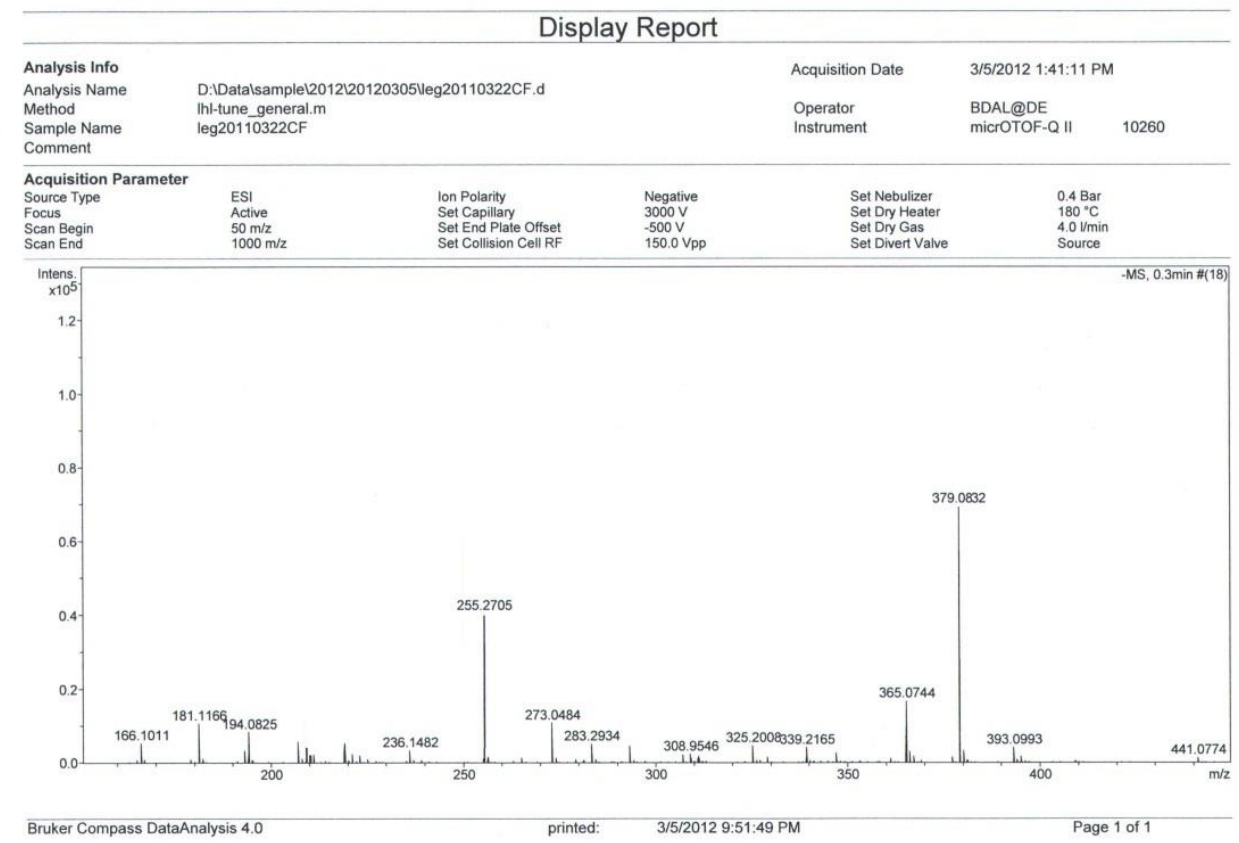

HRMS spectra of compound 1e 


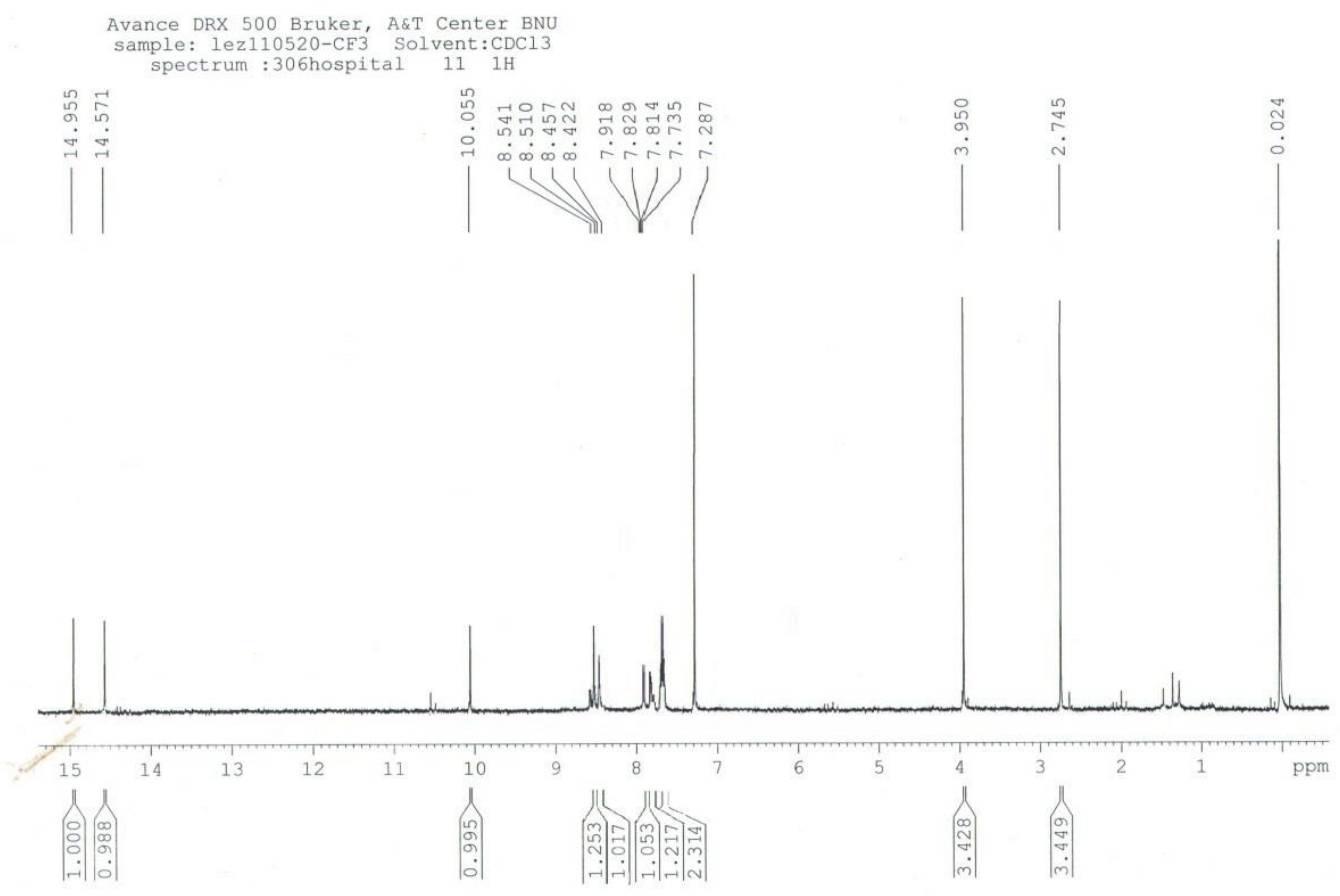

${ }^{1} \mathrm{H}$ NMR spectra of compound 1e

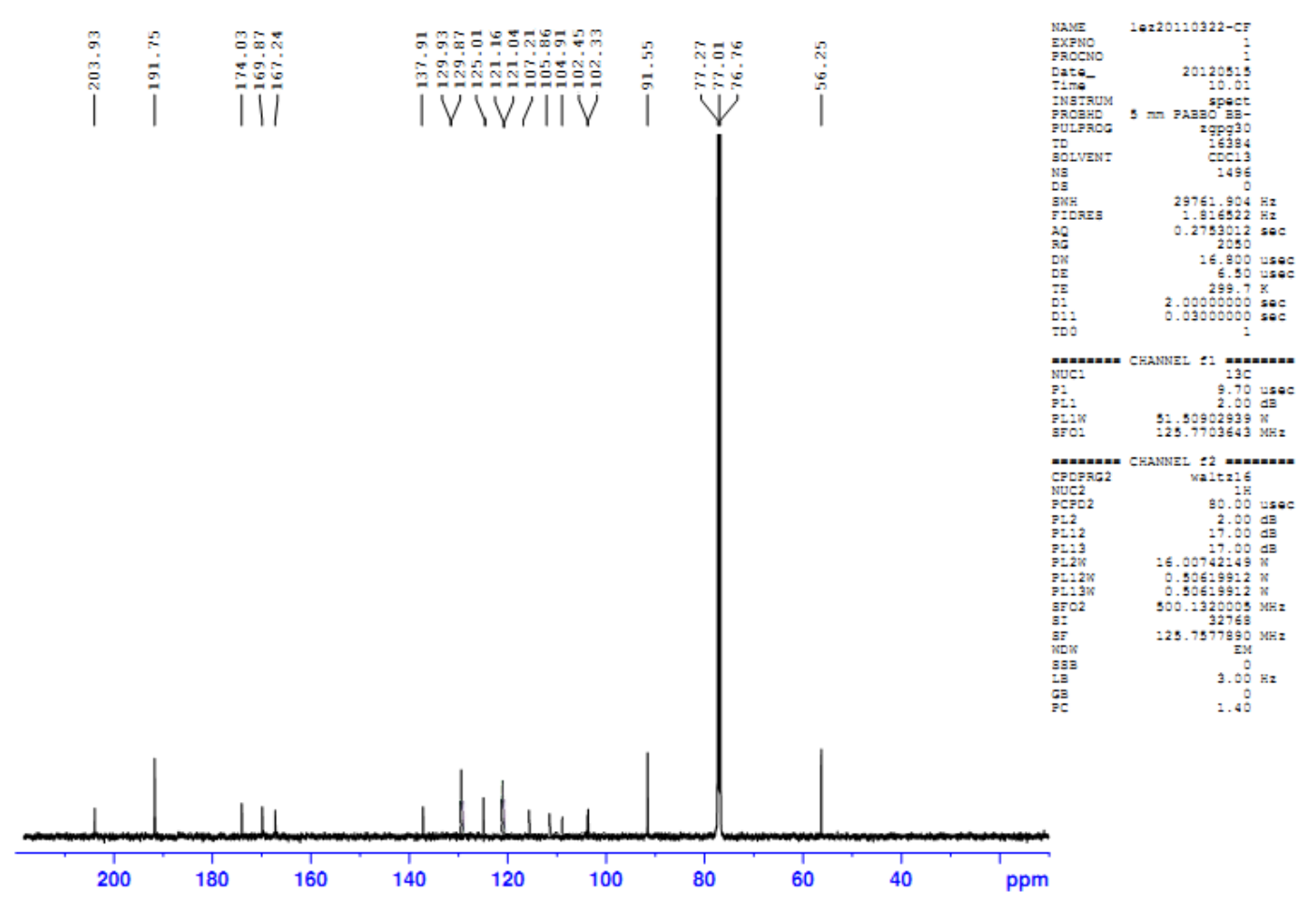

${ }^{13} \mathrm{C}$ NMR spectra of compound $1 \mathrm{e}$ 